\title{
Unemployment clusters across European regions and countries
}

\author{
Henry G. Overman*‡ \\ London School of Economics \\ Diego Puga*§ \\ University of Toronto
}

\author{
Centre for Economic Performance Discussion Paper 434 \\ July 1999. Revised March 2000
}

\begin{abstract}
European regions experienced a polarisation of their unemployment rates between 1986 and 1996. Regions with high or low initial unemployment saw little change, while regions with intermediate unemployment moved towards more extreme rates. This polarisation was driven by employment changes. Labour force changes partly mitigated polarisation. We develop a non-parametric approach to show that unemployment rates are more similar across neighbouring regions than across regions in the same State or with similar characteristics. Regardless of their initial position, regions experienced similar changes to those of neighbours. Surprisingly, this similarity persists after controlling for common characteristics, and is equally strong across national borders.
\end{abstract}

Key words: unemployment, European regions, distribution dynamics.

JEL classification: R12, E24, F15.

*We thank Carlos Gradín for help in calculating the polarisation measure, and Danny Quah for making his econometric shell tsrF publicly available. We are also grateful to Gilles Duranton, Maia Güell, Hubert Jayet, Angelo Melino, Andrew Oswald, Nadia Soboleva, Dan Trefler, and participants at various seminars for helpful discussions. This paper was started while DP was visiting CEP, continued while HGO was visiting UofT, and concluded while both authors were visiting NHH. The hospitality of these institutions is greatly appreciated.

$¥$ Also affiliated with the Centre for Economic Performance at the London School of Economics. Funding from the United Kingdom Economic and Social Research Council is gratefully acknowledged.

$\S$ Also affiliated with the Canadian Institute for Advanced Research, the Centre for Economic Performance at the London School of Economics, the Centre for Economic Policy Research, and the Norges Handelshøyskole. Funding from the Social Sciences and Humanities Research Council of Canada, and from the Connaught Fund and the Joint Research Initiative of the University of Toronto is gratefully acknowledged.

Correspondence addresses:

Henry G. Overman

Department of Geography and Environment

London School of Economics

Houghton Street

London wC2A $2 \mathrm{AE}$

United Kingdom

h.g.overman@lse.ac.uk

http://cep.lse.ac.uk/ overman
Diego Puga

Department of Economics

University of Toronto

150 St. George Street

Toronto, Ontario M5s 3G7

Canada

d.puga@utoronto.ca

http://dpuga.economics.utoronto.ca 


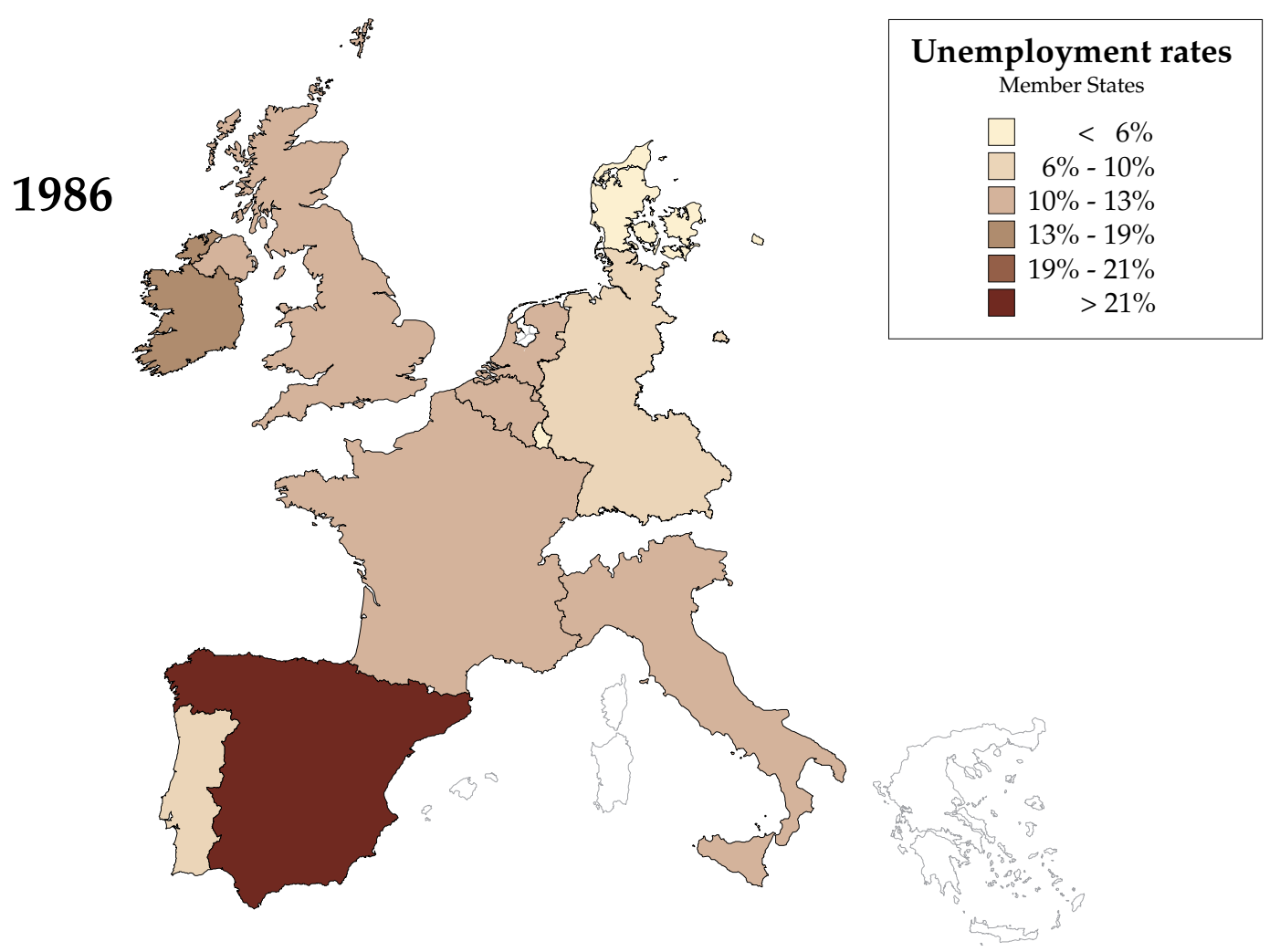

Figure 1. National unemployment rates in Europe

\section{Introduction}

When we think about differences in unemployment rates across Europe, we normally think of differences across countries as represented in Figure 1. However, national averages hide large differences in unemployment rates across regions within countries. The case of Italy is best known, with Campania having a 1996 unemployment rate 4.4 times as high as Valle d'Aosta. But large regional differences exist in all European countries. In the United Kingdom, in 1996, Merseyside had an unemployment rate 3.2 times that of the Surrey-Sussex region; in Belgium, the unemployment rate of Hainut was 2.2 times that of Vlaams Brabant; in France, Languedoc-Roussillon had a rate twice that of Alsace; and so on.

This leads naturally to the question of whether State membership is the best way to group regions when we want to understand their unemployment outcomes. The maps in Figure 2 plot 1986 and 1996 regional unemployment rates for the contiguous European Community of 1986 (more details on the regional coverage are given in Section 2). Casual inspection suggests that characterising regional unemployment outcomes in terms of alternative groupings may be at least as useful as characterising them in terms of national groupings. For instance, we see clusters of neighbouring regions with similar unemployment rates. Perhaps these clusters are a more useful way of characterising unemployment outcomes? Of course, geographical groupings are only one way of thinking about this issue. Regions differ in the skill structure of their populations and in the sectoral composition of their employment, as well as in their geographical location within the 


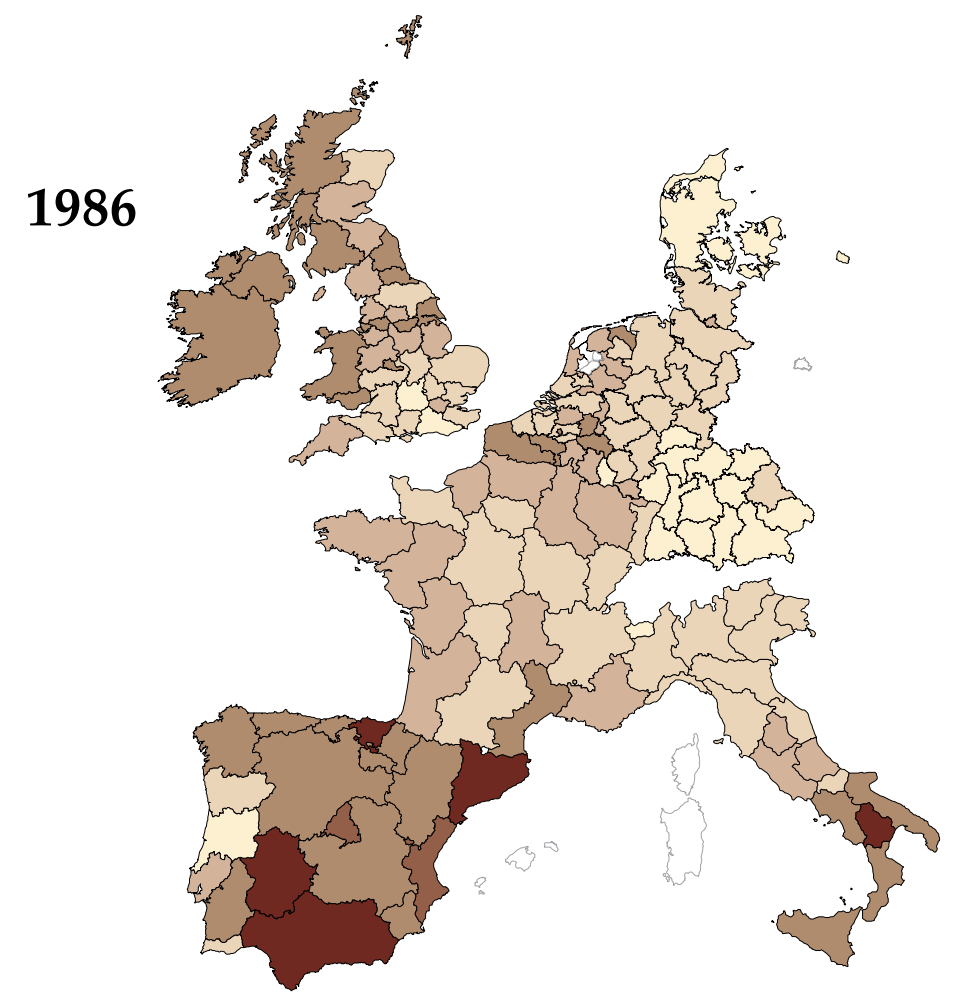

\begin{tabular}{|c|}
\hline Unemployment rates \\
NUTs2 regions \\
$<6 \%$ \\
$\square \quad 6 \%-10 \%$ \\
$\square 10 \%-13 \%$ \\
$\square 13 \%-19 \%$ \\
$19 \%-21 \%$ \\
$>21 \%$ \\
$\square \quad$
\end{tabular}

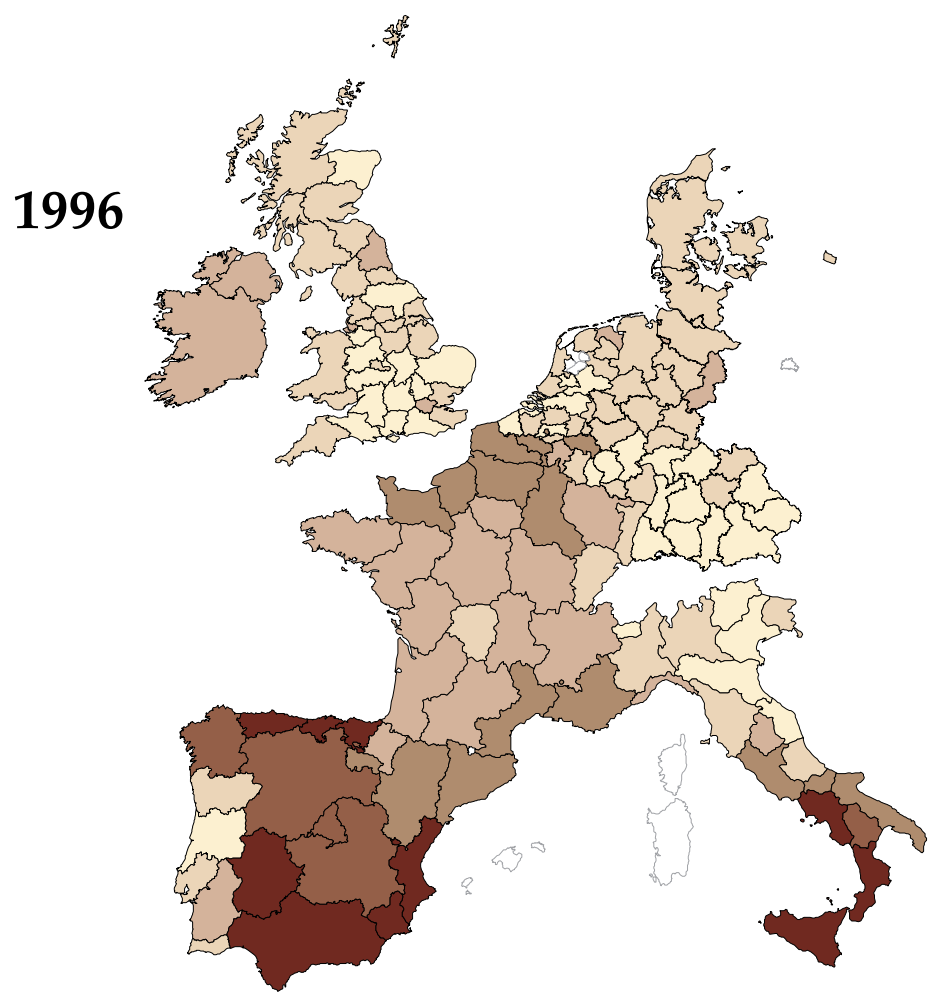

Figure 2. Regional unemployment rates in Europe 
European Union (EU). Perhaps we would be better-off thinking about skilled versus unskilled regions, or about agricultural versus manufacturing versus service regions?

In the first part of this paper (Section 3), we develop a nonparametric approach that allows us to compare the usefulness of such alternative groupings. The technique involves grouping regions by some common characteristic (like State Membership, geographical contiguity, skill or sectoral composition), and then examining the similarity of outcomes (such as unemployment) within groups. Because this technique is nonparametric, it allows different regional characteristics to matter to different degrees for different parts of the distribution - as turns out to be the case. Applying this approach to unemployment leads us to conclude that clusters of neighbouring regions, often extending across national boundaries, are very similar in terms of their unemployment outcomes. Presumably, neighbouring regions share a number of common characteristics. However, we show that grouping regions by some of these common characteristics yields much more heterogeneous outcomes within each group than when we compare across neighbours.

In the second part of the paper (Section 4), we turn to the evolution of regional unemployment rates from 1986 to 1996. In the previous decade, the average European unemployment rate had been rising. However, differences in unemployment rates across European regions were very stable, with changes in regional labour forces just offsetting ongoing changes in regional employment (see chapter 6 in Layard, Nickell, and Jackman, 1991). The map at the bottom of Figure 2 suggests that something has changed over the last decade, and that the stability described by Layard et al. (1991) up to the mid-1980s no longer holds. The average unemployment rate for regions in these maps was the same, 10.7\%, in 1996 as in 1986, and the decade separating them could be thought of as covering a full cycle in unemployment rates ${ }^{1}$. Yet the map for 1996 looks different enough from that for 1986, that one starts to wonder what has happened to the distribution of European regional unemployment rates over this period.

To examine this, we look at the evolution of the shape of the distribution of European unemployment rates. Further, we track the outcomes of individual regions. We find that regions that had a low unemployment rate relative to the Eu average in 1986 still tended to have a relatively low unemployment rate in 1996. Similarly, regions that had a relatively high unemployment rate in 1986 still tended to have a relatively high unemployment rate in 1996. However, regions with intermediate initial unemployment rates had mixed fortunes. Some saw their relative unemployment rate fall markedly, while others saw it rise, and still others saw it roughly unchanged. As a result, the distribution of regional unemployment rates has become increasingly polarised into a group of high unemployment regions and a group of low unemployment regions. An appropriate measure shows a $37 \%$ increase in polarisation over this decade. We also show that polarisation has been due to changes in regional employment. Changes in labour forces have mitigated, but not offset, this employment-driven polarisation.

This polarisation has been the result of different regions with intermediate initial unemployment rates moving in opposite directions over the decade. What do regions that have seen their

\footnotetext{
${ }^{1}$ The average European unemployment rate in 1986 (for regions belonging to what was then the European Economic Community) was $10.7 \%$, starting to come down from a peak of $10.8 \%$ one year before that. It kept coming steadily down to $8.1 \%$ in 1990, and then steadily up to a new peak of $11 \%$ in 1994, after which it fell back to its 1986 rate of $10.7 \%$ in 1996.
} 
unemployment rates increase have in common? Likewise, what is similar about those regions that have seen their unemployment rates fall? Our results from Section 3 suggests that one important feature that they have in common is that they tend to be neighbours.

To examine the connection explicitly, we study the relationship between changes in regional unemployment outcomes and the outcomes of neighbouring regions (Section 5). To make sure that this relationship is predominantly driven by geographical location rather than common characteristics, we move from our nonparametric approach to more standard parametric regression techniques. This allows us to look at more than one factor at a time, although at the expense of the detail provided by the nonparametric technique. We find that, even after conditioning out the effect of common characteristics, the neighbour effect remains strong and significant. Further, when we separate the effect of domestic and foreign neighbours, we find no significant difference between them.

Over the last decade European regions' unemployment outcomes have closely followed those of neighbouring regions. This is only weakly explained by regions being part of the same Member State, having a similar skill composition, or broad sectoral specialisation. Remarkably, neighbouring regions across national borders are as important as domestic neighbours in understanding unemployment outcomes. The polarisation of unemployment that has occurred over the last decade has been characterised by the emergence of clusters of high and low unemployment, which show little respect for national borders.

\section{Data}

We study Europe relative unemployment rates from 1986 to $1996^{2}$. The Europe relative unemployment rate is defined as the ratio of the regional unemployment rate to the European-wide average unemployment rate. Working with relative, as opposed to absolute unemployment rates, helps remove co-movements due to the European-wide business cycle and trends in the average unemployment rate. As mentioned in the Introduction, the average European unemployment rate was the same in 1996 as in 1986, 10.7\%, and the decade in between can be regarded as covering a full cycle.

The unemployment rate series are computed from the harmonised unemployment rates and labour force data contained in the Regio database produced by Eurostat (Eurostat, 1998). These data are based on the results of the Community Labour Force Survey, carried out in Spring each year.

The analysis focus on the contiguous European Community of 1986. That is, those regions of the Eu that satisfy the following three criteria:

1. Have been part of the EU (European Economic Community before 1 November 1993) from 1986 to 1996.

2. Are in a Member State which has a land border with at least one other Member State containing at least one region satisfying (1).

\footnotetext{
${ }^{2}$ Unfortunately, only a much more limited regional coverage is available before 1986. In addition, serious comparability problems arise when using data for earlier years.
} 
3. Have a land border with at least one other region satisfying (1) and (2).

The definition of regions corresponds to level two of the Nomenclature of Territorial Units for Statistics (NUTS2), a hierarchical classification with three regional levels established by Eurostat to provide comparable regional breakdowns of EU Member States. There are 150 NUTS2 regions satisfying criteria (1) to (3). The average NUTS2 region in our data set had a land area of 13,800 square kilometres and a population of 2.1 million in 1996 (that is slightly larger than the Us State of Connecticut and with two thirds of its population).

The Data Appendix gives full details of the regional coverage and data sources.

\section{Grouping regions}

How do we set about characterising the salient features of the distribution of regional unemployment rates? In this section, we make a start by considering a nonparametric method which allows us to identify groups of regions that have similar unemployment outcomes.

The idea is to look at how close each region's unemployment rate is to that of some group of regions which we would expect to behave similarly. To do this we establish a mapping from a region's unemployment rate relative to the European average to the same region's unemployment rate relative to the group average. We group regions by a number of different criteria. Specifically, we group regions in the same Member State, regions that are geographical neighbours, regions with similar sectoral composition, or regions with similar proportions of low skilled.

The nonparametric approach we develop builds on a collection of tools proposed by Quah (1996, 1997a) for studying the dynamics of evolving distributions. The most common application of these tools has been to look at transitions within a given distribution over time. For a discrete distribution this involves computing standard transition probability matrices, which give the probability of moving between different discrete states. For a continuous distribution, this involves estimating a stochastic kernel - the continuous equivalent of the transition probability matrix. In the Appendix, we show that a similar construction can be used to explain the mapping between any two distributions, not just distributions of the same variable at different points in time. In our case this approach involves estimating the stochastic kernel mapping regional outcomes relative to the European average to regional outcomes relative to the group average.

To make this concrete, think about grouping together regions that belong to the same Member State.

\section{Grouping by Member State}

We often think of regional unemployment outcomes as predominantly determined by country outcomes. In this section, we use our nonparametric technique to formally assess how close regions' unemployment outcomes are to those of other regions in the same Member State.

Consider the extreme case, where all regions within each State have (almost) identical unemployment rates. In that case, any differences in regional unemployment rates correspond to regions being in States with different national unemployment rates. In this extreme benchmark 

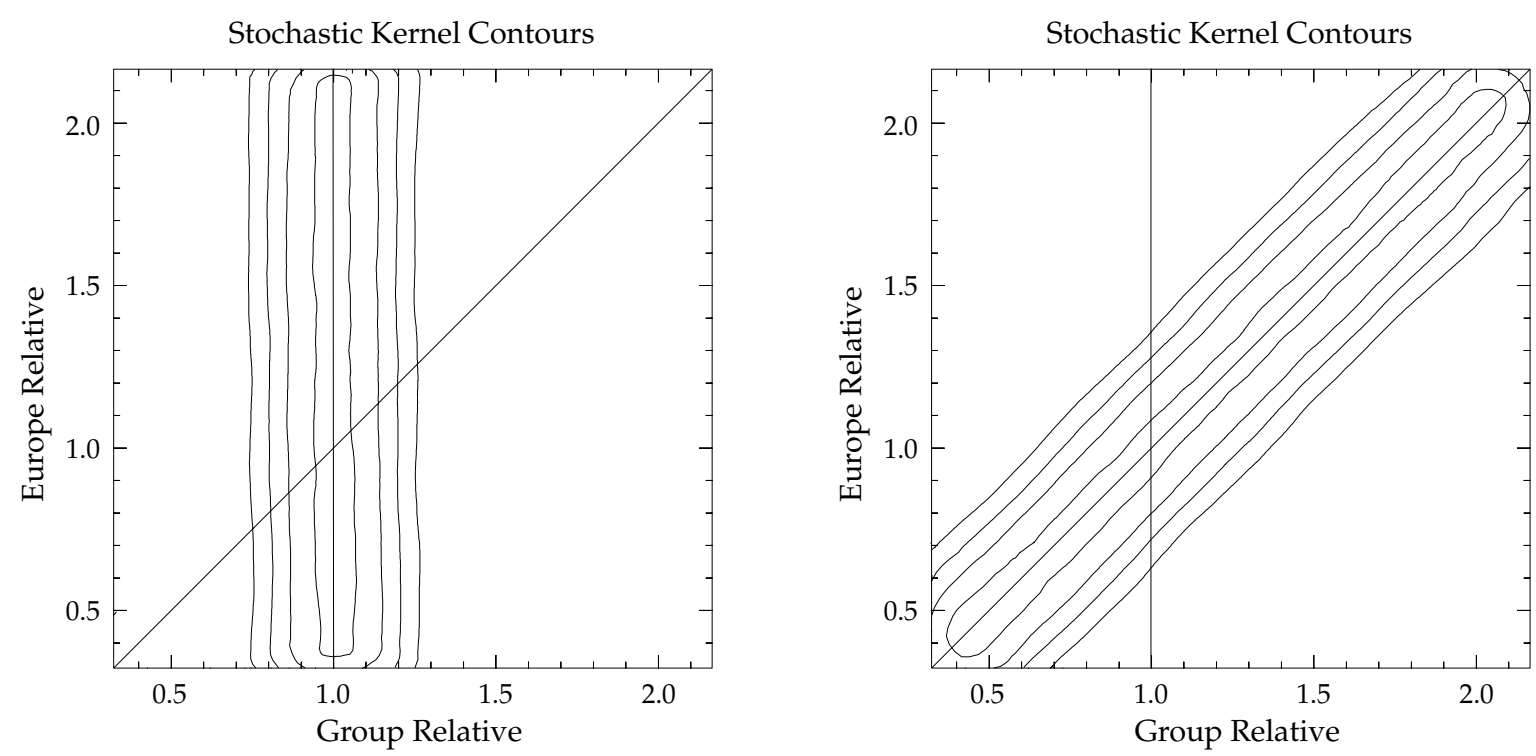

Figure 3. Benchmark stochastic kernels

case, regardless of a region's Europe relative unemployment rate, its unemployment relative to the average for other regions in the same Member State (State relative) will be close to one. The stochastic kernel mapping Europe relative to State relative unemployment rates will then have (almost) all mass centered around one. The contour plot on the left of Figure 3 illustrates this benchmark.

The stochastic kernels in this paper are represented in two ways - as three dimensional diagrams and as contour plots. To read the three-dimensional kernels, imagine taking a cross-section perpendicular to the Europe relative unemployment axis at some value: this gives the distribution of group relative (in this case, State relative) outcomes conditional on that value of Europe relative unemployment. The stochastic kernel plots this conditional distribution for all possible values of Europe relative unemployment. A related way to think about the kernels is to imagine taking ranges of Europe relative and group relative unemployment rates and integrating under the kernel. Just like a cell in a transition probability matrix, this value gives us the probability of a region in the chosen range of Europe relative outcomes also being in the chosen range of group relative outcomes. Similar to the contours on a geographical map, the lines on the plots in Figure 3 connect points at the same height on the corresponding three dimensional kernel. So to read the contour plot on the left of Figure 3, you need to picture a 'mountain range' running 'north-south' with the crest of the range around one - the figure plots the contours of this mountain range.

The contour plot on the right of Figure 3 illustrates the opposite extreme. For this benchmark, there is a similar regional distribution within each State and (almost) identical State averages. In this case, high Europe relative unemployment rates correspond to high State relative unemployment rates (and vice-versa). The stochastic kernel mapping Europe relative to State relative unemployment rates then has (almost) all mass concentrated on the diagonal.

As we move through the kernels in the remainder of the paper, it will be useful to keep these two benchmarks in mind. Our objective will be to find a grouping criterion that produces a kernel 

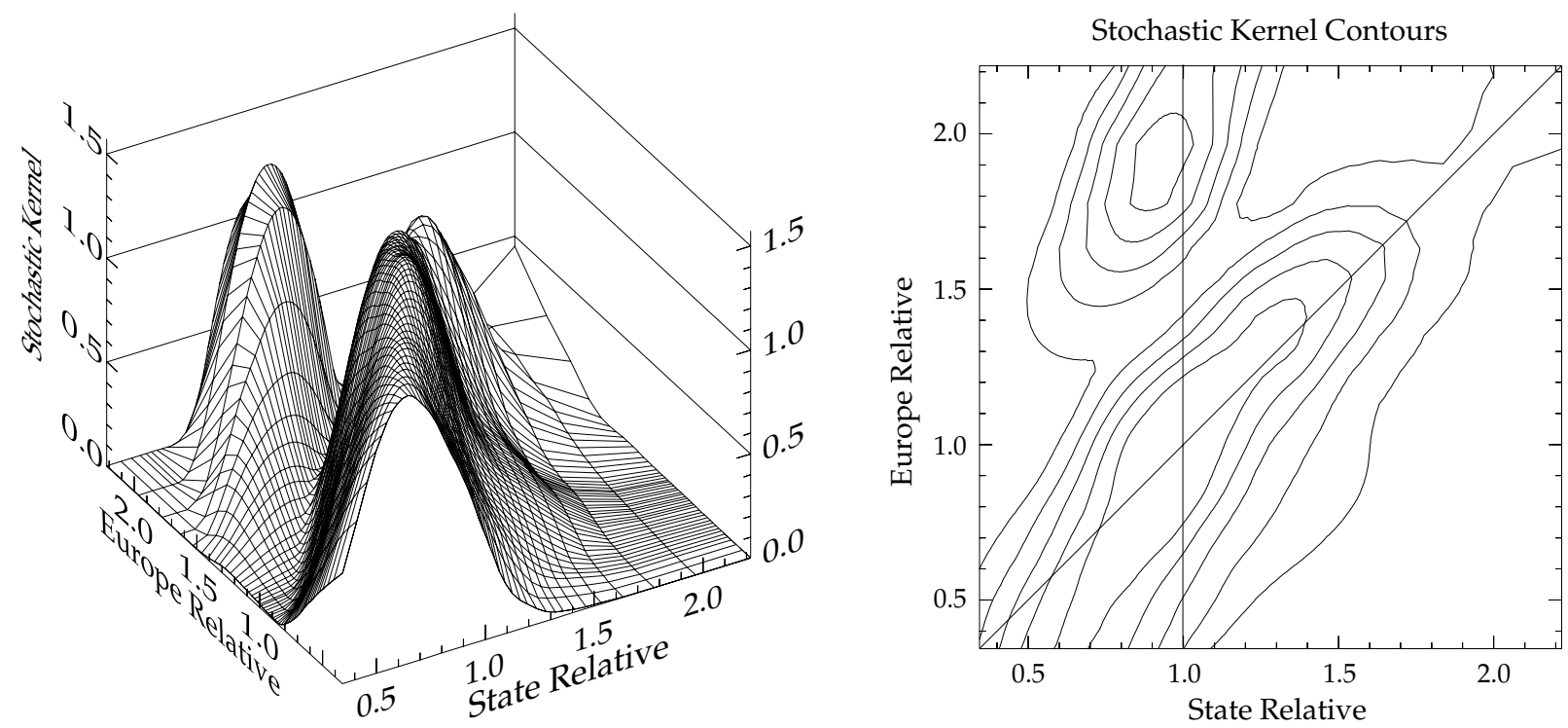

Figure 4. Europe relative to State relative stochastic kernel

as close as possible to the benchmark on the left of Figure 3, and as different as possible from the benchmark on the right.

In reality we see neither of these extremes. Figure 4 shows the actual Europe relative to State relative stochastic kernel. The kernel is calculated using data for all eleven years ${ }^{3}$. For unemployment rates below 1.5 times the European average, the kernel is concentrated close to the diagonal, showing that each region's position with respect to the European average is not dissimilar from its position with respect to its State average.

In contrast, for the range above 1.5 times the European average, some high Europe relative unemployment outcomes correspond to high State outcomes. The spike at around the European average in this range corresponds to approximately one half of Spanish regions with unemployment rates close to the Spanish average, plus Ireland ${ }^{4}$ prior to 1994. However, there are also regions in this range whose outcome differs as much from their State average as from the European average, leading to a wide spread of mass to the right of the vertical line at one and close to the diagonal. This was a small group of regions in 1986, formed by Basilicata and Campania in Southern Italy, Northern Ireland, and five regions in the North of England and the South of Scotland. Over the next decade the British regions dropped from this group as their unemployment rates came closer to those of their Southern neighbours. At the same time, this group expanded to include regions on both sides of the French-Belgian border, all of Southern Italy, and the regions on France's

${ }^{3}$ To estimate the kernel, we first derive the joint distribution of Europe relative and Group relative unemployment rates. We then numerically integrate under this joint distribution with respect to Group relative rates, to get the marginal distribution of Europe relative rates. Finally, we estimate the marginal distribution of Group relative rates conditional on Europe relative rates by dividing the joint distribution by the marginal distribution. Calculations were performed with Danny Quah's tSrF econometric shell (available from http://econ.lse.ac.uk/ dquah/). The three dimensional stochastic kernel plots are drawn so that the density of lines reflects the underlying number of observations on which that part of the kernel is estimated. This procedure makes the pictures easier to read and more informative without changing the shape of the kernel.

4Ireland is classified as a single NUTS2 region, so by construction its regional unemployment rate is always the State average 

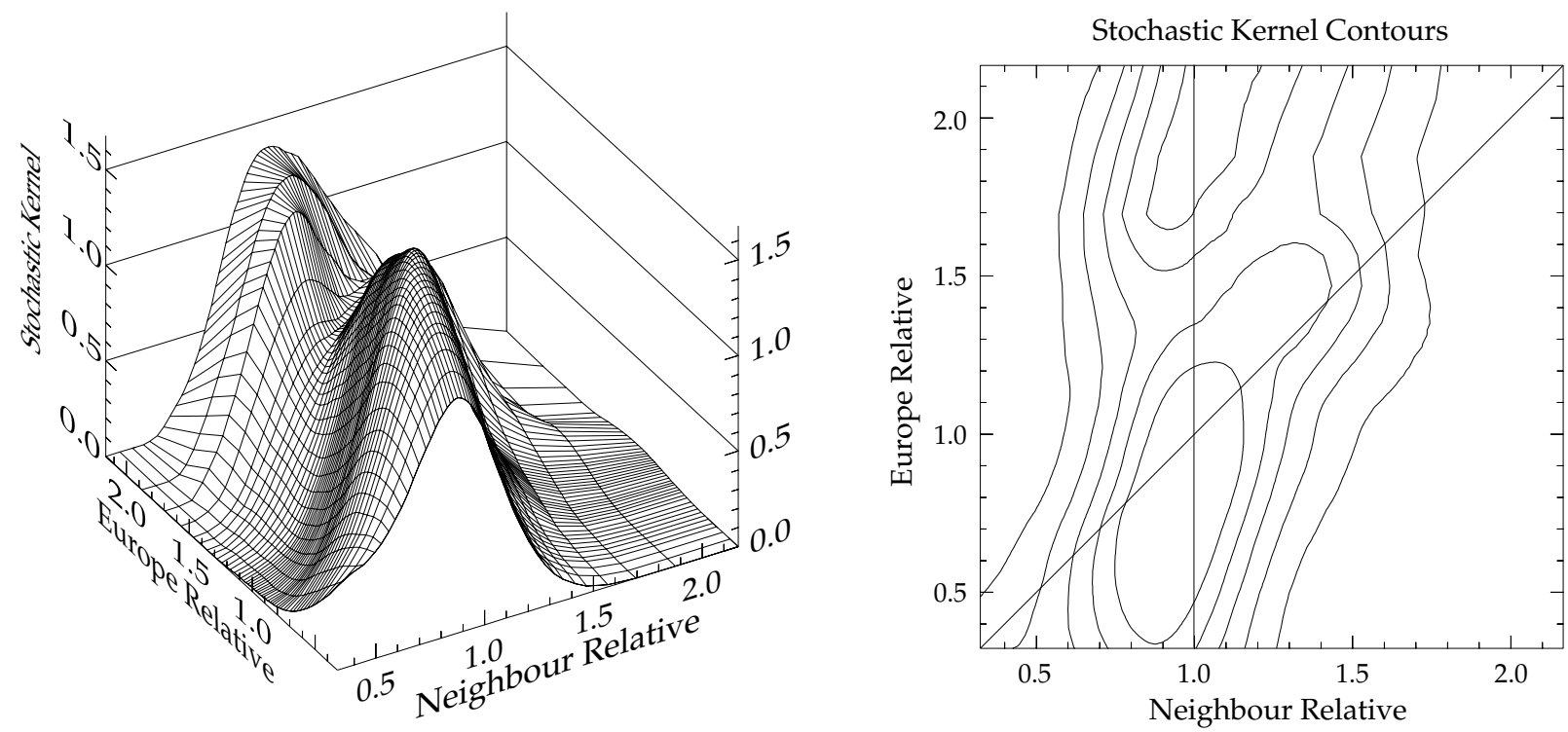

Figure 5. Europe relative to neighbour relative stochastic kernel

Mediterranean Coast.

\section{Grouping geographical neighbours}

We have seen that only regions with the very highest unemployment regions have outcomes similar to other regions in the same Member State. Might it be more useful to compare unemployment outcomes to those of neighbouring regions?

To answer this question we construct a kernel mapping Europe relative to neighbour relative unemployment rates, defined as each region's unemployment rate divided by the labour force weighted average of the unemployment rates of contiguous regions (including foreign neighbours, but not including the region itself).

Comparison of Figure 5 with Figure 4 shows that regional unemployment outcomes are much closer to the outcomes of neighbouring regions than to the outcomes of regions in the same Member State. Although the neighbour relative kernel still twists towards the diagonal for the middle unemployment regions, it is far more concentrated around the vertical line at one. This shows that while regions may have had different outcomes relative to the European average, they had very similar outcomes to those of their neighbours. This difference is particularly clear when one contrasts Figures 4 and 5 in the 'twist' of the bottom peak and the 'depth' of the valley between the two peaks in the three dimensional plot. Alternatively, one can count up the number of lines from the 'bottom' of the contour plot in Figures 4 and 5 (they are plotted at the same heights). Both the lower peak and the valley between the peaks in the neighbour relative kernel incorporate far more mass than the corresponding areas in the State relative kernel. The depth of the valley is particularly relevant, because, as we will see in Section 4, it is in this intermediate unemployment range that regions with similar starting positions had very different evolutions. Also, note that a regions' domestic neighbours are part of the groups used to construct both kernels. In Figure 5, however, other regions in the same State are included. In Figure 4 they are not, but foreign 

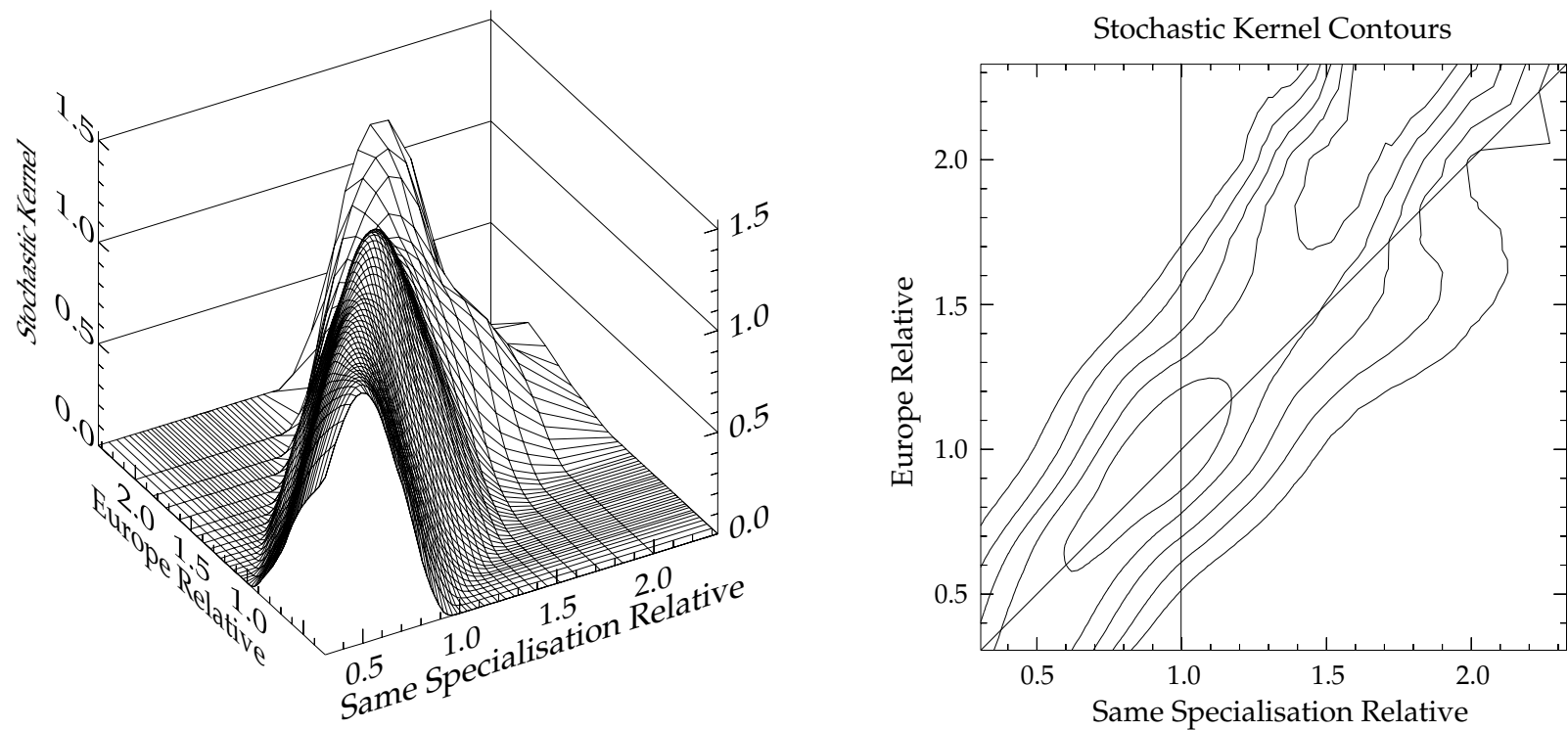

Figure 6. Europe relative to same specialisation relative stochastic kernel

neighbours are. This suggest that foreign neighbours may be more closely related to a region than regions in the same State that are not contiguous — an issue to which we will return below.

The similarity of outcomes across neighbours could simply be driven by neighbouring regions having similar characteristics that are important determinants of unemployment rates. We now turn to two such determinants.

\section{Grouping by broad sectoral specialisation}

The period 1986 to 1996 saw the continuation of an ongoing shift of European employment from agriculture, mining, and industry into services. In the absence of counteracting labour force changes, this may have resulted in high unemployment rates for regions with initial specialisation in declining sectors. Could the similarity across neighbours be a result of regions with heavy industrial or primary employment being contiguous? Figure 6 suggests that the answer is no. This figure shows the stochastic kernel mapping Europe relative unemployment rates to same specialisation relative unemployment rates. To do this, we group regions by the sector (agriculture and other primary sectors, manufacturing, or services) in which the initial share of regional employment was highest, relative to the average European share.

The concentration of mass on the diagonal of Figure 6 suggests that regions with similar initial specialisation have seen very different outcomes. This is probably due to the fact that the largest drop in agricultural and manufacturing employment had already taken place before the beginning of the period we consider. In the 15 years between 1971 and 1986 the share of manufacturing in European employment fell from $41 \%$ to $33 \%$, while the share of services rose from $45 \%$ to $59 \%$. In the next ten years to 1996, the share of manufacturing only fell by another three percentage points to $30 \%$, while that of services rose to $65 \%$. Spatial concentrations of declining sectors are not the key component driving the neighbour effect. 

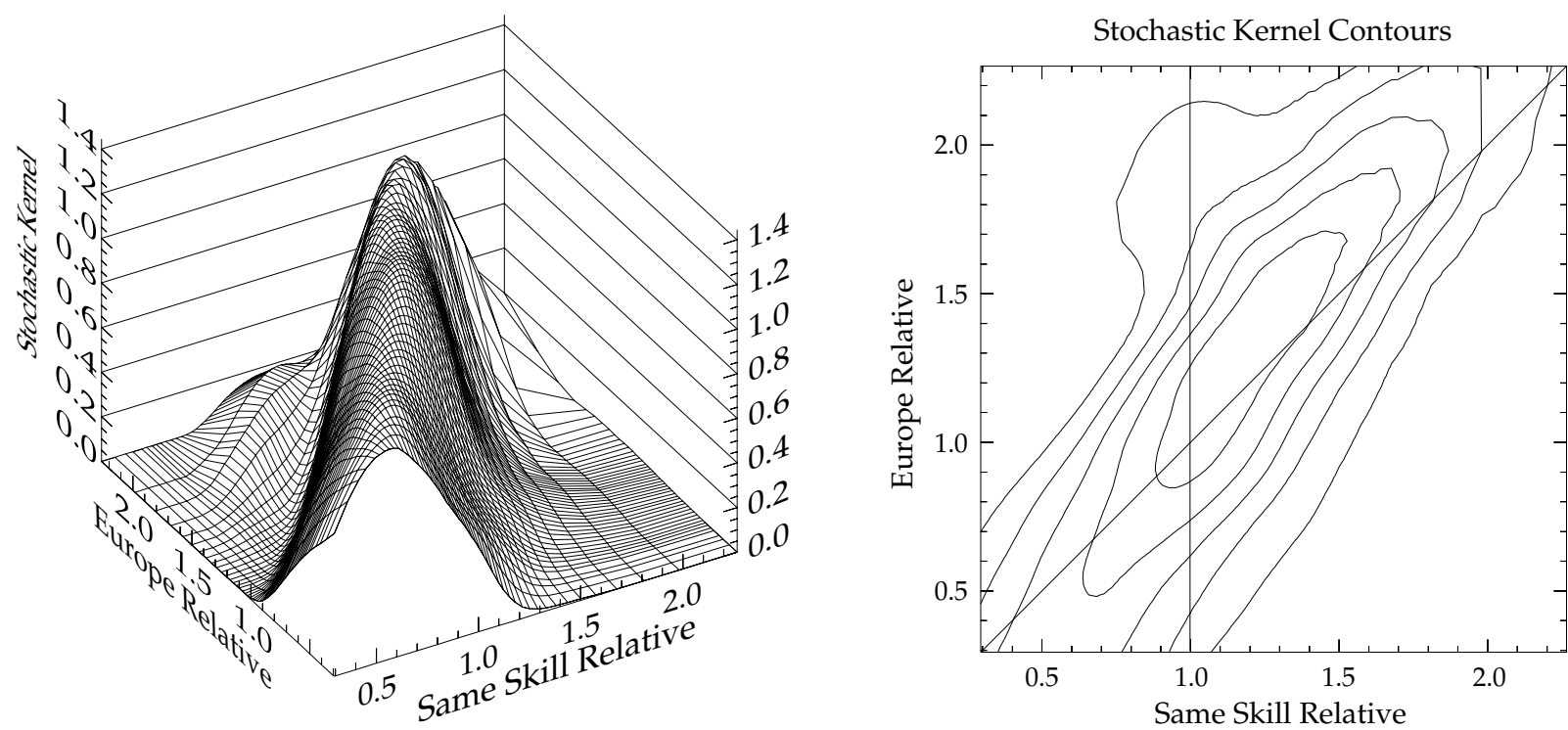

Figure 7. Europe relative to same skill relative stochastic kernel

\section{Grouping by similar skill composition}

There has been some discussion as to whether changes in the patterns of relative labour demand and supply in Europe have resulted in a rise in unemployment rates for the low skilled relative to the high skilled (see, for instance, Nickell and Bell, 1995; Manacorda and Petrongolo, 1998). If this is the case, regional unemployment outcomes may reflect the underlying skill composition of regional labour forces. Have regions with a large proportion of low skill workers experienced similarly high unemployment outcomes, while regions with a small proportion of low skill workers experienced similarly low unemployment outcomes?

Figure 7 plots the stochastic kernel mapping Europe relative to same skill relative unemployment rates. We construct the kernel using nine groups of regions that have a similar percentage of adult population with less than upper secondary education (divided into equally spaced intervals between $0 \%$ and $90 \%$ ). The concentration of mass on the diagonal reflects the fact that the distribution of unemployment rates across each of our nine groups of regions with similar skill composition is not dissimilar from the distribution of unemployment rates across all European regions. Spatial concentrations of similarly skilled regions are clearly not the key component driving the neighbours effect either.

\section{Discretisation}

In order to check the visual ranking of the kernels, we discretise the state space of relative unemployment rates and calculate the transition matrices that are the discrete versions of the continuous stochastic kernels. These discretisations, presented in Table 1, allow us estimate the relative mass in different areas of the kernels without having to integrate explicitly5.

5The matrices give two additional pieces of information. The second column gives the ranges that we have used to discretise the distribution. The first column gives $n$, the number of regions that have Europe relative unemployment in any given range. 


\begin{tabular}{|c|c|c|c|c|c|c|}
\hline$n$ & & & \multicolumn{2}{|c|}{ State Relative } & \multirow[b]{2}{*}{0.13} & \multirow[b]{2}{*}{0.38} \\
\hline 240 & {$[1.45-\infty)$} & 0.00 & 0.06 & 0.43 & & \\
\hline 201 & [1.15-1.45) & 0.00 & 0.13 & 0.16 & 0.52 & 0.18 \\
\hline 577 & {$[0.75-1.15)$} & 0.00 & 0.05 & 0.68 & 0.18 & 0.09 \\
\hline 330 & {$[0.55-0.75)$} & 0.06 & 0.30 & 0.50 & 0.12 & 0.02 \\
\hline 302 & {$[0-0.55)$} & 0.30 & 0.36 & 0.32 & 0.01 & 0.00 \\
\hline & & $0-0.55)$ & [0.55-0.75) & {$[0.75-1.15)$} & [1.15-1.45) & {$[1.45-\infty)$} \\
\hline
\end{tabular}

\begin{tabular}{|c|c|c|c|c|c|c|}
\hline \multicolumn{3}{|l|}{$n$} & \multicolumn{2}{|c|}{ Neighbour Relative } & \multirow[b]{2}{*}{0.30} & \multirow[b]{2}{*}{0.21} \\
\hline 240 & {$[1.45-\infty)$} & 0.00 & 0.04 & 0.45 & & \\
\hline 201 & {$[1.15-1.45)$} & 0.00 & 0.06 & 0.40 & 0.37 & 0.16 \\
\hline 577 & {$[0.75-1.15)$} & 0.01 & 0.07 & 0.63 & 0.21 & 0.07 \\
\hline 330 & {$[0.55-0.75)$} & 0.04 & 0.16 & 0.72 & 0.07 & 0.01 \\
\hline 302 & {$[0-0.55)$} & 0.22 & 0.17 & 0.55 & 0.06 & 0.00 \\
\hline & & $0-0.55)$ & {$[0.55-0.75)$} & {$[0.75-1.15)$} & {$[1.15-1.45)$} & {$[1.45-\infty)$} \\
\hline
\end{tabular}

\begin{tabular}{|c|c|c|c|c|c|c|}
\hline$n$ & \multicolumn{6}{|c|}{ Same Specialisation Relative } \\
\hline \multirow{4}{*}{ 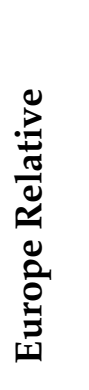 } & {$[1.45-\infty)$} & 0.00 & 0.00 & 0.01 & 0.25 & 0.74 \\
\hline & {$[1.15-1.45)$} & 0.00 & 0.00 & 0.35 & 0.36 & 0.29 \\
\hline & {$[0.75-1.15)$} & 0.00 & 0.15 & 0.68 & 0.16 & 0.01 \\
\hline & {$[0.55-0.75)$} & 0.23 & 0.45 & 0.32 & 0.00 & 0.00 \\
\hline 302 & {$[0-0.55)$} & 0.68 & 0.32 & 0.00 & 0.00 & 0.00 \\
\hline & & $0-0.55)$ & {$[0.55-0.75)$} & {$[0.75-1.15)$} & {$[1.15-1.45)$} & {$[1.45-\infty)$} \\
\hline
\end{tabular}

\begin{tabular}{|c|c|c|c|c|c|c|}
\hline \multicolumn{3}{|l|}{$n$} & \multicolumn{2}{|c|}{ Same Skill Relative } & \multirow[b]{2}{*}{0.24} & \multirow[b]{2}{*}{0.61} \\
\hline 240 & {$[1.45-\infty)$} & 0.00 & 0.00 & 0.15 & & \\
\hline 201 & {$[1.15-1.45)$} & 0.00 & 0.01 & 0.28 & 0.56 & 0.14 \\
\hline 577 & {$[0.75-1.15)$} & 0.00 & 0.11 & 0.64 & 0.18 & 0.07 \\
\hline 330 & {$[0.55-0.75)$} & 0.17 & 0.33 & 0.41 & 0.07 & 0.02 \\
\hline 302 & {$[0-0.55)$} & 0.48 & 0.25 & 0.26 & 0.00 & 0.00 \\
\hline & & $0-0.55)$ & {$[0.55-0.75)$} & {$[0.75-1.15)$} & {$[1.15-1.45)$} & {$[1.45-\infty)$} \\
\hline
\end{tabular}

Table 1. Europe relative to group relative transition probability matrices 
To interpret these matrices it is useful to compare them with the same benchmarks we used to interpret the corresponding stochastic kernel: large numbers on the column for the interval containing one, versus large numbers on the diagonal. We see that the Europe relative to neighbour relative matrix has all diagonal elements smaller than those of the other three kernels. At the same time, all other elements in the central column are larger in the Europe relative to neighbour relative matrix.

This confirms our earlier conclusion, that the unemployment outcomes of individual regions are much closer to the outcomes of their neighbours, than to the average outcomes of other regions within the same Member State, or other regions with the same sectoral specialisation, or skill composition. That suggests that there is a truly spatial component to the neighbour effect - an issue to which we return in Section 5.

\section{The evolution of the distribution of unemployment rates}

\section{The shape of the distribution}

So far, we have been considering features of the cross-sectional distribution of unemployment outcomes. Now, we want to consider what happened to the distribution of European regional unemployment rates over the decade 1986 to 1996 . We start by plotting, in Figure 8, a sequence of kernel estimates of the density of Europe relative unemployment rates for four years: 1986, 1989, 1993, and $1996^{6}$ The density plots can be interpreted as the continuous equivalent of a histogram, in which the number of intervals has been let tend to infinity and then to the continuum. By definition, 1 on the horizontal axis indicates the European average unemployment rate, 2 indicates twice the average, and so on.

Two features are particularly noticeable in Figure 8. First, as we move through the decade, the distribution of unemployment rates for a majority of regions becomes more concentrated below the European average: the peak of the distribution, close to the average in 1986, moves slightly leftwards and the mass becomes more narrowly concentrated around that peak. Second, there is a growing group of regions with unemployment rates above twice the European average: these regions produce the 'bulge' in the upper tail of the distribution — to see this clearly, contrast the mass above twice the European average unemployment rate in 1986 and 1996. Looking through the four snapshots we see that these two features have slowly evolved over the decade. Therefore, over time more regions have experienced unemployment rates below the European average, or above twice that average, and less regions have unemployment rates between the average and twice the average.

\section{Polarisation}

The density plots are suggestive of a gradual polarisation of European regional unemployment rates. However, this interpretation cannot be supported by the density plots alone. The collection of

\footnotetext{
${ }^{6}$ All densities are calculated nonparametrically using a Gaussian Kernel with bandwidth set as per section 3.4.2 of Silverman (1986). The range is restricted to the positive interval using the reflection method proposed there.
} 

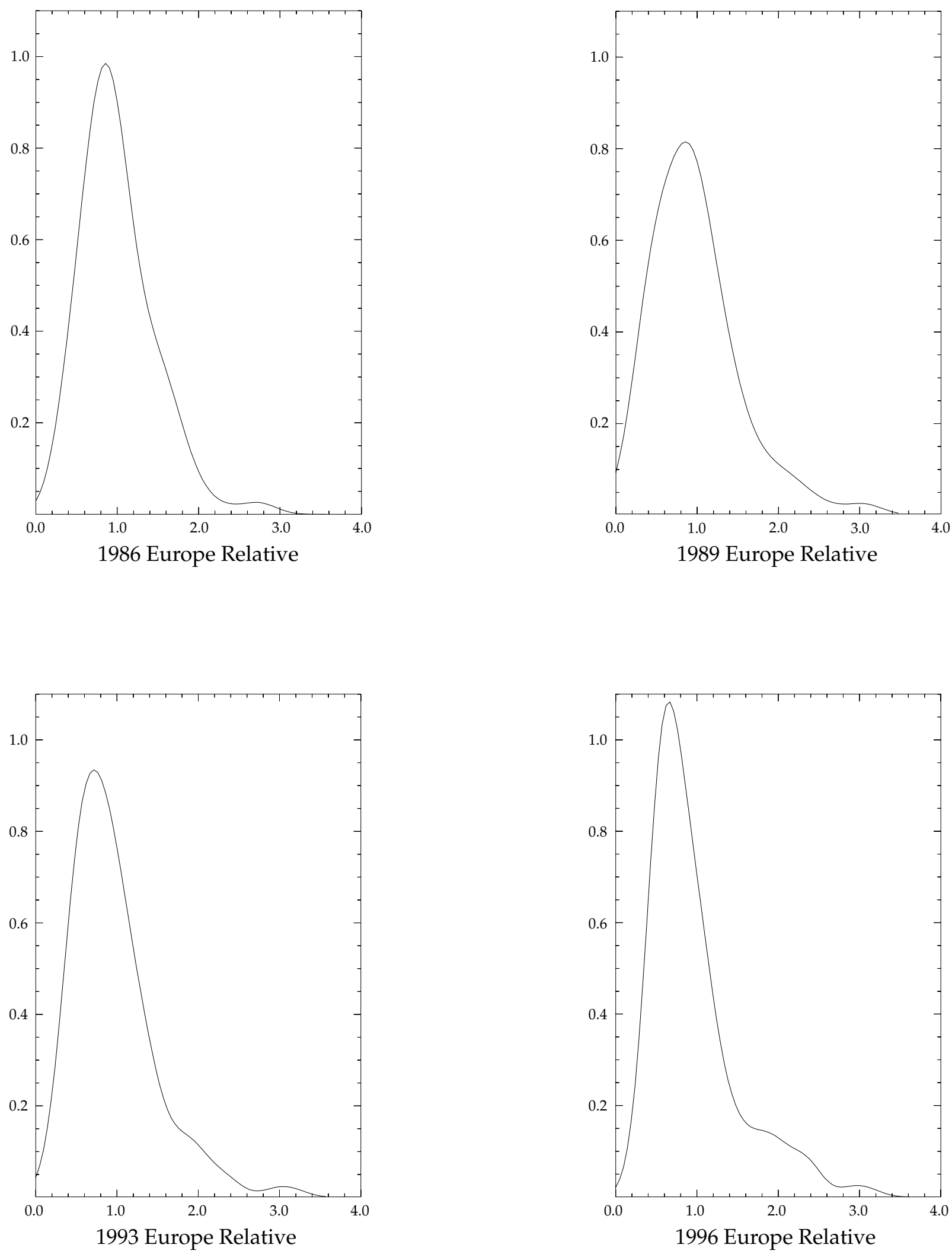

Figure 8. Densities of Europe relative unemployment rates 

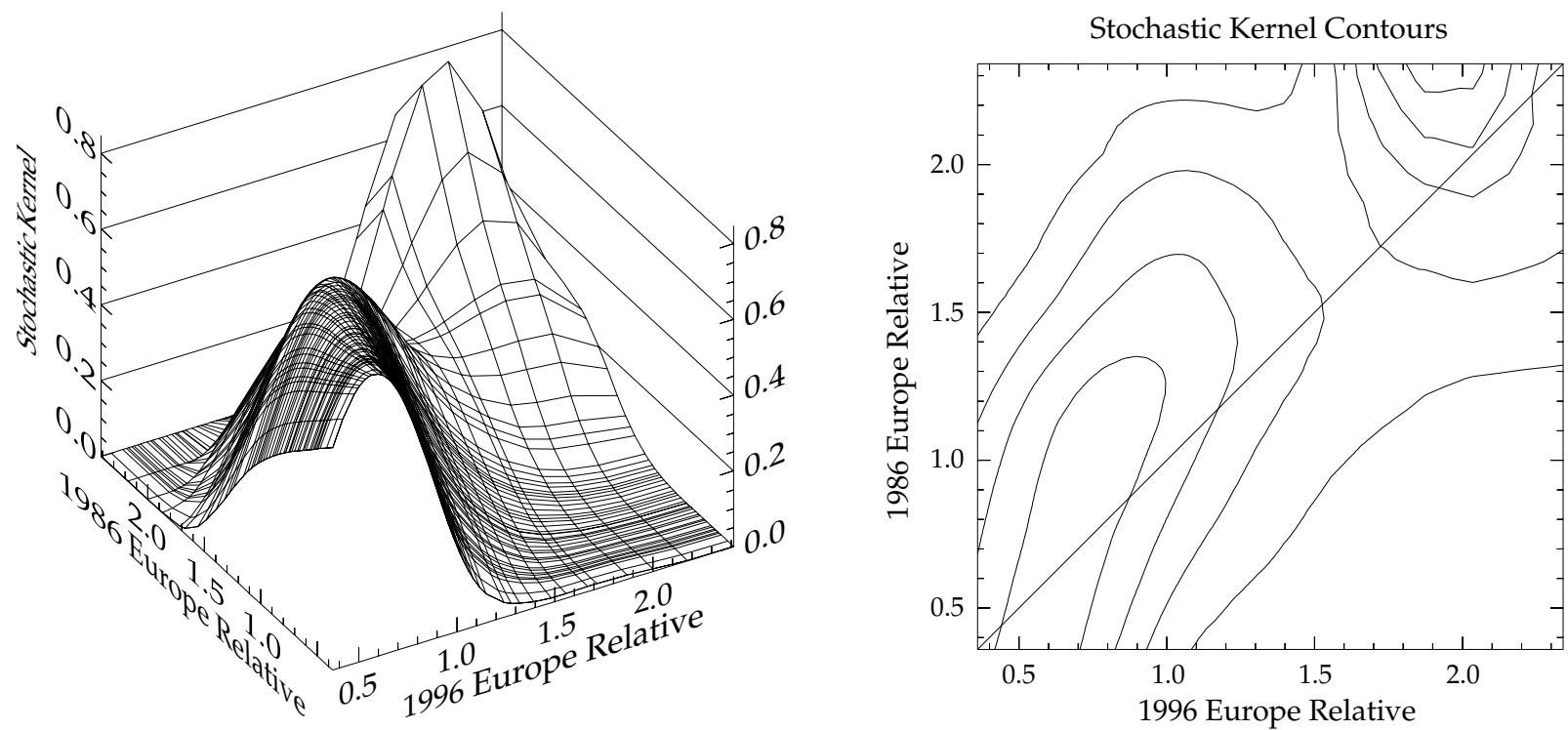

Figure 9. 1986 to 1996 Europe relative Stochastic Kernel

densities tell us nothing about the identity of regions in the distribution of regional unemployment rates. Is it true that a group of low unemployment regions and a group of high unemployment regions has slowly emerged, while regions with intermediate unemployment rates have moved closer to the tails of the distribution? Certainly, more regions had low or high unemployment rates in 1996 than in 1986, but what was their relative position in the earlier year? Does this collection of snapshots actually just show churning of the unemployment rate distribution, the random ups and downs of regional fortunes, or are they the result of a more structured process?

The natural way to answer these questions is to track the evolution of each region's relative unemployment rate over time. To do this, we calculate the stochastic kernel mapping the distribution of Europe relative unemployment rates in 1986 to the distribution of Europe relative unemployment rates in 1996 - the results are reported in Figure 9. This kernel works in exactly the same way as the grouping kernels that we used in Section 3, except that here we are looking at transitions in the Europe relative distribution over time. As before, the plot on the right hand side of the figure is a contour plot of the three dimensional kernel on the left. An additional straight line is drawn on the contour plot to mark the diagonal, where all mass would be concentrated if there was complete persistence in the distribution.

Figure 9 confirms that there has been a polarisation of regional unemployment rates between 1986 and 1996. Regions that in 1986 had a low unemployment rate relative to the European average tended to maintain or reduce their unemployment rate over the next decade. Similarly, regions that in 1986 had a high unemployment rate relative to the European average in 1996 still tended to have a relatively high unemployment rate. However, regions with intermediate unemployment rates had mixed fortunes: some saw their relative unemployment rate fall, while others saw it rise. Still others saw it roughly unchanged.

As before, we can check this finding by discretising the state space and constructing the trans- 


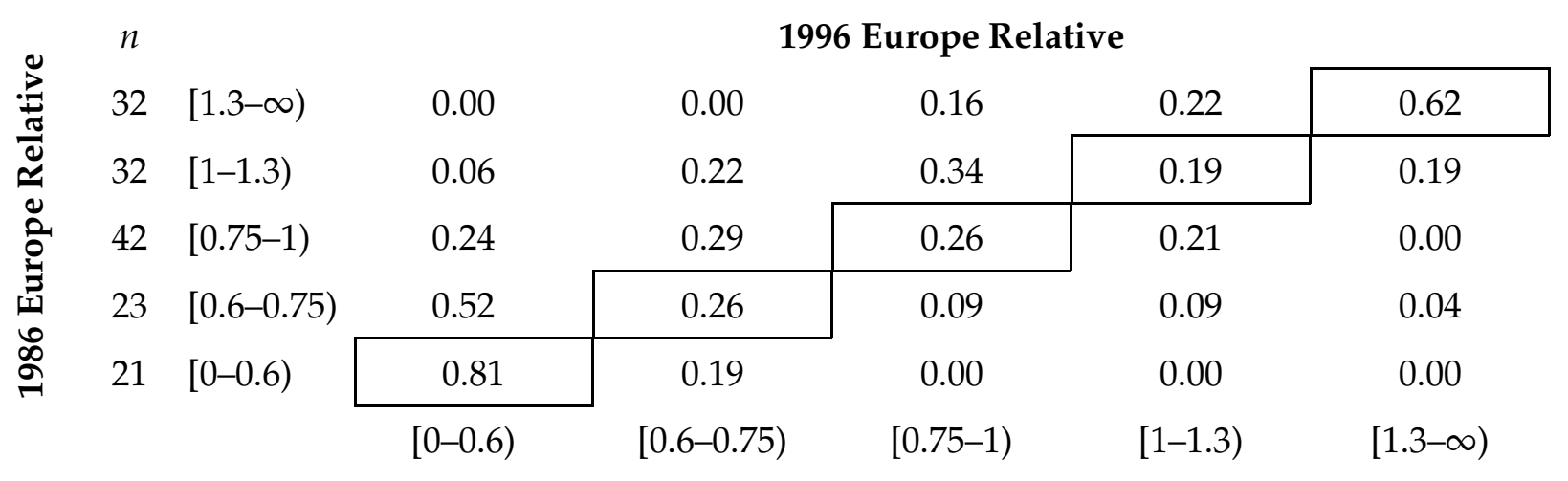

Table 2. 1986 to 1996 Europe relative transition probability matrix

ition probability matrix ${ }^{7}$.

Table 2 reports the transition probability matrix between the 1986 and 1996 distributions of Europe relative unemployment rates ${ }^{8}$. Reading along the bottom row of the matrix, we observe strong persistence for regions starting with an unemployment rate below 0.6 times the European average: by 1996, 81\% remained below 0.6 times the European average, 19\% had an unemployment rate between 0.6 and 0.75 times the average, and none had a relative unemployment rate higher than that. The next row up tells us that of those regions with an initial unemployment rate between 0.6 and 0.75 times the European average, $26 \%$ remained in that range, while $52 \%$ saw their unemployment rate fall below 0.6 times the average. Jumping to the top row we also see strong persistence amongst the regions with highest unemployment rates: of the regions with an initial unemployment rate above 1.3 times the European average, $61 \%$ remained above 1.3 times the average in 1996, while $23 \%$ moved to between the average and 1.3 times the average. However, regions with unemployment rates between 0.75 and 1.3 times the European average (third and fourth rows from the bottom) had experienced much greater mobility - regions with initial unemployment rates between 0.75 times the average and the average ended up almost equally distributed across the four intervals between o and 1.3 times the average. Results from this discretisation confirm our findings of a polarisation of unemployment rates over the decade 1986 to 1996 . We now consider how we might measure the extent of that polarisation.

\section{Measuring Polarisation}

We could calculate and compare a host of summary statistics of the distribution of regional unemployment rates across time. For instance, the Gini coefficient rose from 0.236 in 1986 to 0.281 in 1996. However, the results from the transition kernel in the previous subsection, suggest that the most significant change between 1986 and 1996 has been, not so much an increase in inequality, but

7Europe relative unemployment rates are, by nature, a continuous variable. Constructing a transition probability matrix for a continuous variable requires a discretisation of the space of possible outcomes. There is a degree of arbitrariness involved in choosing a specific discretisation, and changing from one discretisation to another can easily distort the 'true' picture of transitions. In addition, interesting details are lost as a result of the discretisation.

${ }^{8}$ As before, the table gives two additional pieces of information. The first column gives $n$, the number of regions that begin their transitions in a given state. The second column gives the classes that divide up the state space. 

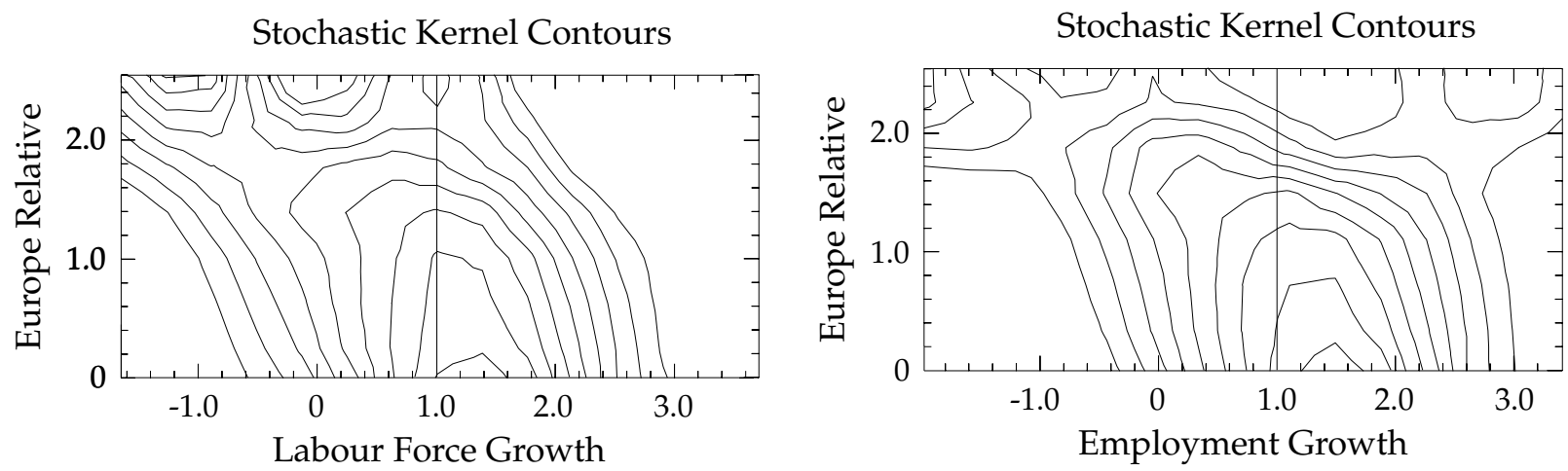

Figure 10. Labour force and employment growth

rather the polarisation of regions into two groups - one with low unemployment and one with high unemployment.

To quantify this polarisation, we use the generalisation by Esteban, Gradín, and Ray (1999) of the polarisation measure of Esteban and Ray (1994). ${ }^{9}$ In the simplest case, for two groups ('high' and 'low' unemployment regions in our case) this polarisation measure is simply

$$
P=2 D-G,
$$

where $D$ is the mean deviation and $G$ is the Gini coefficient. This polarisation measure is high when the density takes the shape of two groups of regions with small differences in unemployment rates within each group and large differences across groups. It increases as regions within each group become more homogenous in terms of their unemployment rates and/or as the two groups move further apart from each other. Between 1986 and 1996 polarisation thus measured increased by $37 \%$, from 0.096 to 0.131 .

\section{What is driving polarisation?}

By definition, unemployment rates equal one minus the ratio of employment to the labour force. Thus, polarisation could be driven by changes in the regional distribution of the labour force (due to some combination of demographic trends, migration patterns, and participation decisions), ${ }^{10}$ as well as by changes in the regional distribution of employment. We can directly test whether it is labour force or employment changes that are driving polarisation.

The plot on the left hand side of Figure 1o graphs the stochastic kernel mapping the distribution of 1996 Europe relative unemployment rates to the distribution of labour force changes between 1986-1996 (relative to the average growth in the European labour force over the decade). The

\footnotetext{
9This generalisation allows the measurement of polarisation without predefined groups. Instead, group membership is endogenously determined so as to minimise the difference between the Lorenz curve of the actual distribution and the piece-wise linear Lorenz curve of the group-discretised distribution. For two groups, the distribution is simply split by the mean.

${ }^{10}$ Labour force changes due to migration are likely to be small. Across European regions net migration flows are tiny, and not very responsive to differences in wages or unemployment rates (see, for instance, Eichengreen, 1993). This is particularly marked for cross-country migration flows, to the extent that only $1.5 \%$ of eu workers have a job in a Member State different from that in which they were born (http://citizens.eu.int/en/en/newsitem-2.htm). In addition, intra-region migration flows have been falling over recent decades.
} 
vertical line at one marks regions with labour force growth equal to the European average, $6.3 \%$. The concentration of mass at the bottom right of the figure shows that most regions that ended up with relatively low unemployment had relatively high labour force growth. Similarly, the concentration of nearly all mass at the top of the figure to the left of one shows that regions that ended up with relatively high unemployment generally had below average labour force growth. Thus, labour force changes have actually worked against polarisation. They have prevented high unemployment regions from having even higher unemployment and low unemployment regions from having even lower unemployment.

The plot on the right hand side of Figure 1o graphs the stochastic kernel mapping the distribution of 1996 Europe relative unemployment rates to the distribution of employment changes between 1986-1996 (again, relative to the European average). The vertical line at one marks regions with labour force growth equal to the European average. The concentration of mass at the bottom right of the figure shows that most regions that ended up with relatively low unemployment had relatively high employment growth. Similarly, the concentration of mass at the top of the figure to the left of one shows that regions that ended up with relatively high unemployment generally had below average employment growth. Thus, contrary to labour force changes, employment changes have worked for polarisation. It is employment changes that have driven high unemployment regions to their high rates and low unemployment regions to their low rates ${ }^{11}$.

\section{Regression results}

In section 3 our main result was that there is a close relationship between the unemployment outcomes of neighbouring European regions. In section 4 we showed that the main feature of the evolution of regional unemployment rates over the decade 1986 to 1996 has been a polarisation into two groups of high and low unemployment. In this section, we relate these two findings to see whether the neighbour effect can help us understand the evolution of unemployment outcomes. In the process of doing this, we also re-examine one possible cause of the neighbour effect - that neighbouring regions have similar characteristics which lead to similar unemployment outcomes. Our results in section 3 grouping by skill and sectoral specialisation suggest that common characteristics only explain a small part of the neighbour effect. Here, we build on those results using a more standard parametric technique to test for the strength of the neighbour effect after conditioning out the effect of a range of regional characteristics ${ }^{12}$.

Specifically, we examine the cross section of changes in regional unemployment rates as a function of State, regional and neighbour characteristics. Table 3, column 1, shows ordinary least

\footnotetext{
${ }^{11}$ These changes in the spatial distribution of employment are probably a response to rapid and deepening European integration over the last decade. Portugal and Spain became Member States in 1986. Customs formalities for shipments of goods across the internal borders of the EU disappeared I January 1993. Border controls for movements of people across Member States signing the Schengen agreement disappeared 26 March 1995. Transport infrastructure has also been greatly improved - for instance, the number of kilometres of motorways increased by a third between 1986 and 1994, and in Portugal and Spain it more than tripled.

${ }^{12}$ The closest counterpart to the stochastic kernel analysis would probably be a suitably defined panel specification. Unfortunately, the lack of reasonable exogenous time varying instruments makes it unfeasible to estimate such a panel, while allowing for the endogeneity of right hand side variables and the (auto)correlation structure of the regional residuals.
} 


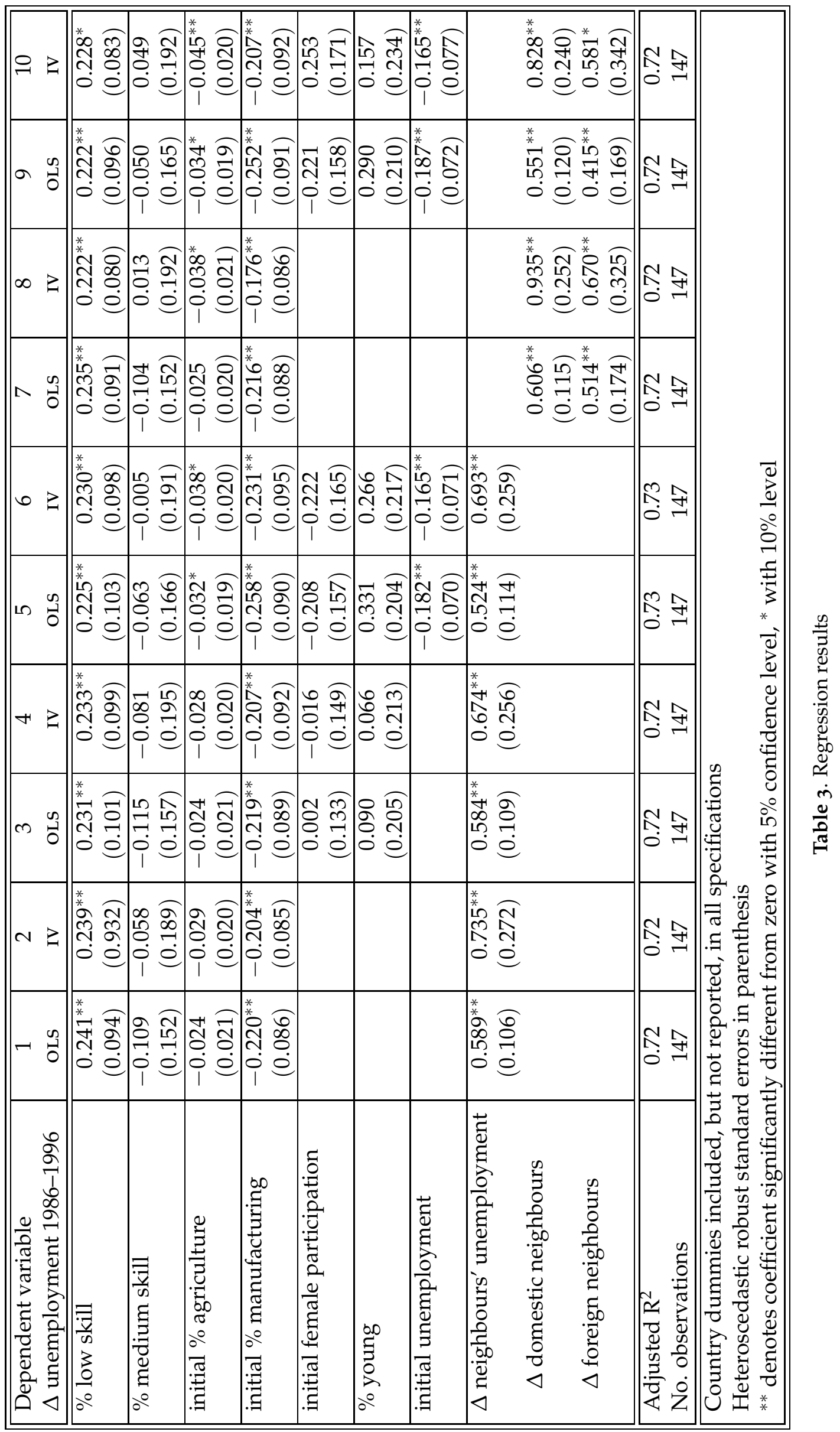


squares results for our first empirical specification. The dependent variable is the (logarithm of the) change in the regional unemployment rate between 1986 and 1996 . We consider a number of different explanatory variables. To capture the neighbour effect, we include the change in neighbours' unemployment rate. This is defined as the labour force weighted average of changes in the unemployment rates of contiguous regions (including foreign neighbours, but not including the region itself). Two variables capture the initial structure of employment in the region - the percentage of regional employment in agriculture, mining, forestry, and fishing, and the percentage of regional employment in manufacturing. Two variables capture the skill composition of the the region - the percentage of adult population with low skills (less than upper secondary education), and the percentage with medium skills (completed upper secondary education). All explanatory variables are expressed in logarithms. Country dummies are included, but not reported, in this and all other specifications. We exclude Member States classified as a single NUTS2 region (Denmark, Ireland, and Luxembourg) from the regressions. Further details on data definitions and sources are given in the Data Appendix. Heteroscedastic robust standard errors are reported in parenthesis.

The coefficient on the percentage of adult population with low skills is positive, large, and significant, as would be expected. After conditioning on the other variables, a high proportion of population with low skills is associated with an increase, or less of a decrease, in regional unemployment. The coefficient on medium skills, however, is not significantly different from zero. This suggests that it is the lower end of the skill distribution that most markedly affects regional labour market outcomes.

The coefficient on the percentage of initial employment in agriculture and other primary sectors is not significantly different from zero. However, the percentage of initial employment in industry has a negative effect on unemployment rate changes. For most of the Northern and Central European regions traditionally specialised in heavy industry, the worst part of the adjustment to their decline was over by the mid 1980s. Since then many of these regions have seen their unemployment rate fall. Adjustment has taken place later in heavy industrial regions in Southern Europe. Since the latter have a higher proportion of population with low skills, this can explain why, after controlling for skills, the effect of manufacturing specialisation on unemployment changes is negative.

The most remarkable aspect of these results, however, is that the evolution of the unemployment rate in neighbours has a very strong and significant effect, even after controlling for common characteristics. Thus, common characteristics are not driving the neighbour effect. Before interpreting this result further, we discuss a number of econometric issues.

We capture the neighbour effect through changes in neighbours' unemployment, rather than through covariance assumptions on the error structure, because we want to capture the impact of predictable increases in neighbouring unemployment. Such expected increases are, by definition, orthogonal to the error, and thus best captured through the inclusion of a 'spatially lagged' dependent variable ${ }^{13}$. However, spatially lagged dependent variables are correlated with the error (a region's unemployment affects its neighbour's unemployment, which in turn affects the region's

${ }^{13}$ See Anselin (1988) for further discussion. 
unemployment, and so on). To solve this endogeneity problem, we instrument for the spatially lagged dependent variable.

Neighbour's initial sectoral employment shares, and the skill, age and sex composition of their workforces are all possible instruments for the spatially lagged unemployment rates. We would also like to instrument for the movement of firms and workers across regions. Location theories suggest that such movements will be related to some measure of 'market potential' ${ }^{14}$. Thus, we construct an additional instrument based on a simple market potential variable, defined as the inverse distance weighted sum of European regional Gross Domestic Products ${ }^{15}$. Instrumental variables (IV) results using this set of instruments are presented in Table 3, column 2. This shows that instrumenting does not change our initial results. The proportions of low educated and initial industrial employment remain significant. The effect of neighbours' unemployment remains strong and significant ${ }^{16}$.

Our second specification introduces two additional variables. Because European youth unemployment rates are high and rising, and regions differ in the age structure of their population, we control for the percentage of population that reached working age during the period (those aged between 15 and 25 in 1996). Additionally, in the mid-1980s female participation rates differed widely across regions. Some regions, in Spain, had participation rates as low as $18 \%$, while others, in the UK, had rates above $50 \%$. Over the decade, female participation rates significantly converged across regions. This has resulted in large labour force increases in some regions, potentially affecting unemployment rates ${ }^{17}$. We therefore control for the initial female participation rate in each region. OLs results are in column 3. Both coefficients have the expected sign, but are insignificant. Further investigation reveals that the percentage young becomes significant if we drop percentage low skilled and female participation. Female participation remains (just) insignificant when we drop percentage young and low skilled. This occurs because all three variables are highly correlated - although percentage low skilled appears to matter most. Column 4 shows that instrumenting does not change these results.

Column 5 shows oLs results when we introduce the initial unemployment rate. The only change is that initial agriculture employment becomes significant, but only at the $10 \%$ level. Column 6 shows that, once again, instrumenting doesn't change these results.

We have seen that the neighbour effect is strong and significant even after conditioning out similar characteristics. We can also test whether that neighbour effect extends across national borders. To do this, we split the neighbours variable for border regions into two components, that due to domestic neighbours and that due to foreign neighbours ${ }^{18}$. There are $5_{1}$ border regions

\footnotetext{
${ }^{14}$ See Fujita and Krugman (1995) for theoretical foundations, and Hanson (1998) for a recent empirical implementation.

${ }^{15}$ Thus, for region $i$, market potential is defined as $m p_{i}=\sum_{j \neq i} \mathrm{GDP}_{j} / d_{i, j}$, where $d_{i, j}$ is the great circle distance between region $i$ and region $j$, and $\operatorname{GDP}_{j}$ is the $\operatorname{GDP}$ of region $j$, and the sum is over all regions in the European Union excluding region $i$ itself.

${ }^{16}$ In this, and all subsequent specifications we cannot reject the validity of our instrument set at the $5 \%$ confidence level using the test proposed by Davidson and MacKinnon (1993).

${ }^{17}$ See Wasmer (1998) for an exposition of this argument.

${ }^{18}$ For the domestic and foreign neighbours variables, the labour force weights are those used when constructing our original neighbourhood variable. This ensures, that the sum of the two variables is the original neighbourhood variable, and that the coefficients are directly comparable.
} 
(around a third of the sample) ${ }^{19}$. The results from these regressions are reported in Columns 7-10.

Column 7 provides ols results for the basic specification. Both neighbour effects are strong and significant. Further, we are unable to reject the hypothesis that the coefficients on both domestic and foreign neighbours are identical - the test has a value of 0.9 and is distributed $x^{2}(1)$.

Again, both neighbour effects are endogenous, so we instrument for them. The results are reported in Column 8. Both neighbour effects remain strong and significant. Again, we are unable to reject the hypothesis that the coefficients are identical. Next we introduce the additional variables considered before. This specification is presented in Columns 9 (OLS) and 1o (IV). The results are consistent with the previous ones, although the significance of foreign neighbours drops slightly. However, we still cannot reject the hypothesis that the coefficients on both domestic and foreign neighbours are identical.

We have also tried a number of alternative specifications, not reported in the table. For instance, we have tried including the average change in unemployment for regions with a similar initial sectoral specialisation, a similar skill composition of adult population, and so on. The results are still remarkably robust.

Our regression results provide us with a better understanding of the neighbour effect. First, we see that neighbours are important for understanding the evolution of unemployment rates during this process of polarisation. Second, consistent with our results in Section 3, the neighbour effect is not driven by neighbouring regions sharing similar characteristics ${ }^{20}$. Third, the neighbour effect transcends national borders. To further illustrate these findings, we consider the concrete example of two border regions in Belgium.

\section{An example of two border regions in Belgium}

In 1986 the Belgian region of Limburg had an unemployment rate 1.2 times the Belgian average and 1.3 times the European Union average. By 1996 its unemployment rate had fallen below both the Belgian and Eu averages. Just across the border from Limburg (Belgium), two Dutch regions had similar experiences. The unemployment rates of Limburg (Netherlands) and Noord-Brabant fell relative to both the Dutch and Eu averages.

Back in Belgium, 90 kilometres South-West of Limburg and on the border with France, the region of Hainaut started with a similar unemployment rate in 1986. However, instead of falling as it did in Limburg, this rate rose both in absolute terms and relative to both the Belgian and EU averages. Just across the border from Hainaut, the French region of Nord-Pas de Calais also saw its unemployment rate increase in both absolute and relative terms.

\footnotetext{
${ }^{19}$ If we drop out the UK's 35 regions, which include only one border region, then border regions make up nearly half the sample. The results do not change for this restricted sample.

${ }^{20}$ The neighbour effect is also not driven by functional labour markets extending across neighbouring regions with different characteristics. First, from existing work, we know that functional labour markets tend not to extend across NUTS2 regions (see Cheshire and Carbonaro, 1996, for further discussion). Second, neighbourhood effects are equally strong across national borders, and cross border commuting flows are tiny - in 1990 they represented only $0.2 \%$ of the total European labour force. (de Falleur and Vandeville, 1996). Of these roughly $50 \%$ are commutes to Switzerland (not an EU member). Only approximately 100,000 cross-border commuting flows occur across border regions in our sample. Even on the German-French border, where commuting flows are strongest, they represent less than $0.8 \%$ of the combined border region labour force.
} 
The different fortunes of these two Belgian regions were not driven by changes in their labour forces. Both regions had growing labour forces, but Limburg's actually grew more than twice as fast. The reason for Limburg's fall in unemployment is that its employment grew even faster than its labour force, and over four times faster than Hainaut's. A similar process occurred in the two Dutch neighbours of the Belgian Limburg. These regions that did relatively well had large and growing labour forces. But they also had a rate of employment growth that more than matched their labour force growth, and that brought their unemployment rates down. By contrast Nord-Pas de Calais, the French neighbour of Hainaut that did relatively badly, lost employment while its labour force was rising.

The drop in Limburg's unemployment rate versus Hainaut's rise cannot be put down to differences in the skill composition of their labour force. Both these Belgian regions had a similar percentage of their population with less than upper secondary education. And the French region of Nord-Pas de Calais, despite having a smaller fraction of people with less than upper secondary education than either of the Belgian regions, had a worse unemployment outcome.

Further, the evolution of these regions was not due to their different initial sectoral composition. Admittedly in 1986 Nord-Pas de Calais was a predominantly industrial region. But Hainaut also saw its unemployment rate rise and in 1986 was concentrated in services. In contrast, the Belgian success story Limburg was concentrated in industry and of its two neighbours, one was mainly industrial (Noord-Brabant), the other service based (Limburg). No simple story of sectoral changes explains the relative performance of these regions ${ }^{21}$.

Given the small flows of workers across these borders, both in terms of commuting and permanent moves, one can hardly argue that there are functional labour markets extending across these regions. However, firms do seem to find it attractive to exploit other advantages of location close to these borders, such as the ability to use suppliers from different countries. The areas on the borders between Belgium and France and Belgium and the Netherlands have provided traditional locations for industry. However, in recent years these two borders have experienced very different evolutions. The most publicised case came in 1997 as Renault announced the closure of its Vilvoorde plant on the Belgian border with France. This raised protests at the loss of 3,100 jobs, at a time when Renault was planning to expand operations in other parts of Europe. At about the same time in Limburg (Netherlands), Volvo introduced a three-shift working schedule in its Nedcar plant, to double production over the following three years, drawing on suppliers from both sides of the Belgian-Dutch border. And on the Belgian side of this border, General Motors was also expanding production at its Antwerp plant.

Starting from similar intermediate unemployment rates, the Belgian regions Limburg and Hainaut have moved towards opposite extremes of the European distribution, but in each case have gone along with their foreign neighbours. In this paper we have shown that this story is not unique, but representative of a broader pattern that has developed across Europe.

\footnotetext{
${ }^{21}$ Possible differences between the Flemish and French speaking regions of Belgium cannot explain these changes either. Contiguous to both the Flemish speaking Belgian Limburg and to the Dutch Limburg is the French speaking Belgian region of Liège, which also experienced a reduction in its unemployment rate.
} 


\section{Concluding comments}

This paper has shown that over the decade beginning in 1986, the distribution of regional unemployment rates has become polarised with the emergence of a group of high unemployment regions and a group of low unemployment regions. Regions that in 1986 had relatively high or relatively low unemployment have seen their position roughly unchanged. In contrast, regions with intermediate initial rates have had diverse experiences. Some have seen their unemployment rates rise as employment has grown little or even fallen. Relatively low labour force growth has only partly mitigated this weak employment performance. These regions with rising unemployment tend to be contiguous, sometimes in different countries. Other regions with intermediate initial unemployment rates have instead seen their rates fall, as employment growth has outpaced labour force growth. These regions with falling unemployment also tend to be contiguous. While neighbouring regions share many common characteristics, these do not account for their similar unemployment outcomes.

The fact that unemployment outcomes are so much more homogenous across neighbours, foreign and domestic, than across regions in the same Member State highlights the spatial dimensions of the emerging clusters of high and low unemployment in Europe. The average Member State has 13.6 regions, while the average neighbourhood has 5.6 regions. Hence these are clusters of typically less than one half of the size of the average Member State of the European Union, but often extend across national borders and include regions from more than one Member State.

That has important implications for policy. European regional policy has traditionally targeted mainly regional differences in income per capita, but is increasingly shifting its focus towards tackling regional differences in unemployment rates. Contrasting our results with those of Quah (1997b) shows the empirical reality underlying this change in emphasis — in contrast to the divergence of unemployment rates across European regions, Quah shows that differences in regional incomes per capita are narrowing. But there is one important additional difference. While inequalities in incomes per capita exhibited a core-periphery gradient (Keeble, Offord, and Walker, 1988), unemployment clusters are more localised and emerging in both the core and the periphery of the EU. There is strong political opposition to tackling these growing unemployment rate differences through increased labour mobility. However, given that the unemployment clusters we find are of not very large size and scattered across Europe, it may be politically viable as well as more efficient to implement policies that accept some clustering and larger mobility within a neighbourhood.

\section{References}

Anselin, Luc. 1988. Spatial Econometrics: Methods and Models. Dordrecht: Kluwer Academic Publishers.

Centraal Bureau Voor de Statistiek. 1987. Regionaal Statistich Zakboek 1986. The Hague: Centraal Bureau Voor de Statistiek.

Cheshire, Paul and Gianni Carbonaro. 1996. Urban economic growth in Europe: Testing theory and policy prescriptionsl. Urban Studies 33(7): 1111-1128. 
Davidson, Russell and James G. MacKinnon. 1993. Estimation and Inference in Econometrics. New York: Oxford University Press.

de Falleur, M. and V. Vandeville. 1996. Cross-border flows of workers in Europe: Facts and determinants. In Harvey Armstrong and R. W. Vickerman (eds.), Convergence and Divergence Among European Regions. London: Pion, 177-189.

Eichengreen, Barry. 1993. Labor markets and European monetary unification. In Paul R. Masson and Mark P. Taylor (eds.), Policy Issues in the Operation of Currency Unions. Cambridge: Cambridge University Press, 130-162.

Esteban, Joan María, Carlos Gradín, and Debraj Ray. 1999. Extensions of a measure of polarization, with an application to the income distribution of five OECD countries. Processed, Institut d'Anàlisi Econòmica-CSIC, Barcelona.

Esteban, Joan María and Debraj Ray. 1994. On the measurement of polarization. Econometrica 62(4): 819-851.

Eurostat. 1989. Regions: Statistical Yearbook 1988. Luxembourg: Office for Official Publications of the European Communities.

Eurostat. 1990. Regions: Statistical Yearbook 1989. Luxembourg: Office for Official Publications of the European Communities.

Eurostat. 1995. Regions: Nomenclature of Territorial Units for Statistics (NUTS). Luxembourg: Office for Official Publications of the European Communities.

Eurostat. 1997. Education Across the European Union: Statistics and Indicators 1996. Luxembourg: Office for Official Publications of the European Communities.

Eurostat. 1998. Regio Database. Luxembourg: Eurostat. May 1998 CD-ROM version.

Fujita, Masahisa and Paul R. Krugman. 1995. When is the economy monocentric? Von Thünen and Chamberlin unified. Regional Science and Urban Economics 25(4): 508-528.

Hanson, Gordon H. 1998. Market potential, increasing returns, and geographic concentration. Working Paper 6429, National Bureau of Economic Research. URL http: //www . nber . org/.

Keeble, David, John Offord, and Sheila Walker. 1988. Peripheral Regions in a Community of 12 Member States. Luxembourg: Office for Official Publications of the European Communities.

Layard, Richard, Stephen Nickell, and Richard Jackman. 1991. Unemployment: Macroeconomic Performance and the Labour Market. Oxford: Oxford University Press.

Manacorda, Marco and Barbara Petrongolo. 1998. Skill mismatch and unemployment in OeCD countries. Discussion Paper 307, Centre for Economic Performance, London School of Economics.

Nickell, Stephen and Brian Bell. 1995. The collapse in demand for the unskilled and unemployment across the OECD. Oxford Review of Economic Policy 11(1): 40-62.

Quah, Danny T. 1996. Regional convergence clusters across Europe. European Economic Review 40(3-5): 951-958.

Quah, Danny T. 1997a. Empirics for growth and distribution: Stratification, polarisation, and convergence clubs. Discussion Paper 324, Centre for Economic Performance, London School of Economics. URL http://econ.lse.ac.uk/ dquah/. 
Quah, Danny T. 1997b. Regional cohesion from local isolated actions: I. historical outcomes. Discussion Paper 378, Centre for Economic Performance, London School of Economics. URL http://econ.lse.ac.uk/ dquah/.

Silverman, B. W. 1986. Density Estimation for Statistics and Data Analysis. New York: Chapman and Hall.

UNESCO. 1976. International Standard Classification of Education (ISCED). Paris: United Nations Educational, Scientific and Cultural Organization.

Wasmer, Etienne. 1998. Can labour supply explain the rise of unemployment and inequality in OECD countries? Discussion Paper 410, Centre for Economic Performance, London School of Economics. URL http://www.ecare.ulb.ac.be/ecare/etienne/home.htm.

\section{Data Appendix}

Our definition of regions corresponds to level two of the Nomenclature of Territorial Units for Statistics (NUTS), 1995 version (Eurostat, 1995). The NUTS was established by Eurostat to provide comparable regional breakdowns of the Member States of the European Union. It is a hierarchical classification with three regional levels: each Member State is partitioned into an integral number of NUTS1 regions, each of which is in turn partitioned into an integral number of NUTS2 regions, each of which is in turn partitioned into an integral number of NUTS3 regions. (There are two additional sub-regional or local levels, NUTS4 and NUTS5, of which only the latter, consisting of Communes or their equivalent, is defined for all Member States). In 1996 the EU had 77 NUTS1 regions, 206 NUTS2 regions, and 1,031 NUTS3 regions. Eurostat (1995) also calls NUTS2 regions 'Basic Regions', and describes these as the appropriate level for analysing regional-national problems; it is also the level at which both national and Community regional policies are generally implemented.

NUTS2 regions correspond to national administrative units in Austria (Bundesländer), Belgium (Provinces), Finland (Suuralueet), Germany (Regierungsbezirke), Greece (Development Regions), Italy (Regioni), Netherlands (Provincies), Portugal (Comissaoes de Coordenaçao Regional), and Sweden (Riksområden). NUTS2 regions also correspond to national administrative units, but with exceptions, in France (Régions, plus the four Departements d'Outre Mer), and Spain (Comunidades Autónomas, plus Ceuta y Melilla). Three Member States are classified as a single NUTS2 region: Denmark, Ireland, and Luxembourg. In the United Kingdom, Groups of Counties have been introduced as an intermediate (NUTS2) level between NUTS1 (Standard Regions) and NUTS3 (a combination of Counties and Local Authority Regions) units.

The data set includes (with a single exception, documented below) all the NUTS2 regions of the EU that satisfy the following three criteria:

1. Have been part of the EU (European Economic Community before 1 November 1993) from 1986 to 1996.

2. Are in a Member State which has a land border with at least one other Member State containing at least one region satisfying (1).

3. Have a land border with at least one other NUTS2 region satisfying (1) and (2). 
We include as land borders water borders less than five kilometres wide. This leads us to consider as geographical neighbours regions separated by a river (such as Zeelland and Zuid-Holland in Netherlands). It also leads to the inclusion of Sicilia (Italy), which, although an island, is only separated from Calabria (Italy) by the 3,300 metres-wide Strait of Messina - soon to be joined by a single span suspension bridge (see http://www. strettodimessina.it/).

From the 206 NUTS2 regions that formed the EU in 1996, 30 are excluded from the analysis because they were not part of the European Economic Community in 1986: the nine NUTS2 regions of Austria, the six NUTS2 regions of Finland, and the eight NUTS2 regions of Sweden, all of which became part of the EU with the accession of these three Member States in 1995; and the seven NUTS2 regions of Germany that were part of the former Democratic Republic of Germany (Brandenburg, Mecklenburg-Vorpommern, Sachsen, Dessau, Halle, Magdeburg, and Thüringen), which only became part of the eu with German reunification in 1990.

Greece has no land border with any other Member State, so its 13 NUTS2 regions are also excluded.

Finally, another 12 NUTS2 regions are excluded because they have no land border with any other NUTS2 region satisfying criteria (1) and (2): Baleares, Ceuta y Melilla, and Canarias (Spain), Corse, Guadeloupe, Martinique, Guyane, and Réunion (France), Sardegna (Italy), Açores, and Madeira (Portugal), are all entirely surrounded by water and/or by territories which are not part of the EU; Berlin (Germany) is entirely surrounded by NUTS2 regions which were part of the former Democratic Republic of Germany.

Flevoland (Netherlands) is the only region that satisfies criteria (1)-(3) above but has been excluded due to lack of data: there is no labour force or unemployment data for Flevoland for 1986, even from national sources (see Centraal Bureau Voor de Statistiek, 1987). Flevoland was created as a separate administrative unit (Provincie) in 1986 from the union of the Noordoost, Oostelijk Flevoland, and Zuidelijk Flevoland polders, reclaimed from the IJsselllake (a lake that used to be part of Zuiderzee, a former inlet of the North Sea), and in 1996 accounted for $1.8 \%$ of the population and $5.8 \%$ of the land area of Netherlands.

The 150 NUTS2 regions used are:

Belgium (11) Brussels, Antwerpen, Limburg (Belgium), Oost-Vlaanderen, Vlaams Brabant, West-Vlaanderen, Brabant Wallon, Hainaut, Liége, Luxembourg (Belgium), Namur.

Denmark (1)

France (21)

Ile-de-France, Champagne-Ardenne, Picardie, Haute-Normandie, Centre, Basse-Normandie, Bourgogne, Nord-Pas-de-Calais, Lorraine, Alsace, Franche-Comté, Pays de la Loire, Bretagne, Poitou-Charentes, Aquitaine, Midi-Pyrénées, Limousin, Rhône-Alpes, Auvergne, LanguedocRoussillon, Provence-Alpes-Côte d'Azur. 
Stuttgart, Karlsruhe, Freiburg, Tübingen, Oberbayern, Niederbayern, Oberpfalz, Oberfranken, Mittelfranken, Unterfranken, Schwaben, Bremen, Hamburg, Darmstadt, Giessen, Kassel, Braunschweig, Hannover, Lüneburg, Weser-Ems, Düsseldorf, Köln, Münster, Detmold, Arnsberg, Koblenz, Trier, Rheinhessen-Pfalz, Saarland, Schleswig-Holstein.

Ireland (1)

Italy (19)

Piemonte, Valle d'Aosta, Liguria, Lombardia, Trentino-Alto Adige, Veneto, Friuli-Venezia Giulia, Emilia-Romagna, Toscana, Umbria, Marche, Lazio, Abruzzo, Molise, Campania, Puglia, Basilicata, Calabria, Sicilia.

Luxembourg (1)

Netherlands (11)

Groningen, Friesland, Drenthe, Overijssel, Gelderland, Utrecht, NoordHolland, Zuid-Holland, Zeeland, Noord-Brabant, Limburg (Netherlands).

Portugal (5) Norte, Centro (Portugal), Lisboa e Vale do Tejo, Alentejo, Algarve.

Spain (15)

Galicia, Asturias, Cantabria, País Vasco, Navarra, Rioja, Aragón, Madrid, Castilla-León, Castilla-La Mancha, Extremadura, Cataluña, Comunidad Valenciana, Andalucía, Región de Murcia.

United Kingdom (35) Cleveland-Durham, Cumbria, Northumberland-Tyne and Wear, Humberside, North Yorkshire, South Yorkshire, West Yorkshire, DerbyshireNottinghamshire, Leicestershire-Northamptonshire, Lincolnshire, East Anglia, Bedfordshire-Hertfordshire, Berkshire-BuckinghamshireOxfordshire, Surrey-East-West Sussex, Essex, Greater London, HampshireIsle of Wight, Kent, Avon-Gloucestershire-Wiltshire, Cornwall-Devon, Dorset-Somerset, Hereford-Worcestershire-Warwickshire, ShropshireStaffordshire, West Midlands (County), Cheshire, Greater Manchester, Lancashire, Merseyside, Clwyd-Dyfed-Gwynedd-Powys, Gwent-MidSouth-West Glamorgan, Borders-Central-Fife-Lothians-Tayside, DumfriesGalloway-Strathclyde, Highlands-Islands, Grampian, Northern Ireland.

Regional unemployment rates and labour force from 1986 to 1996 are taken from the harmonised unemployment rates (table regio/unemp/un3rt) and labour force (table regio/unemp/un3wpop) in the May 1998 version of the Regio database published by Eurostat (Eurostat, 1998).

These data are based on the results of the Community Labour Force Survey (LFs). The Community LFS is carried out in Spring each year and for each Member State provides the number of the unemployed (in accordance with the definition of the International Labour Office), and the labour force (labelled 'working population') for April. The national unemployment data are subsequently regionalised to NUTS2 level on the basis of the number of persons registered at unemployment offices in April of the reference year (with the exceptions of Greece, Spain, Italy, Portugal, Finland, and Sweden, where the regional unemployment structures are taken from the Community LFS). The national labour force data are regionalised to NUTS2 level according to the results of the Community LFs. The regional unemployment rates are then obtained by dividing the number of the unemployed by the labour force.

The Regio database has no data on unemployment rates or labour force for two years, 1986 and 1987, for 13 of the targeted regions: all the NUTS2 regions of Netherlands, and Algarve (Portugal). 
For all of them (except the Dutch region of Flevoland, as documented above) comparable data has been obtained as follows. For the NUTS2 regions of the Netherlands in 1986 and 1987, the total number of the unemployed in the Netherlands in table /regio/unemp/un3pers of the Regio database has been regionally disaggregated to NUTS2 level, on the basis of the number of the unemployed in each region from table II.4 of Eurostat (1989), which are also derived from the Community LFS. Similarly, the total labour force of the Netherlands in table /regio/unemp/un3wpop of the Regio database has been regionally disaggregated to NUTS2 level, on the basis of regional labour force figures from table II.2 of Eurostat (1990) (for 1986), and of regional labour force figures computed by dividing the number of the unemployed by the corresponding unemployment rates in table II.4 of Eurostat (1989) (for 1987). Regional unemployment rates have then been calculated by dividing the number of the unemployed by the labour force. For Algarve (Portugal) in 1986 and 1987, employment and unemployment figures have been privately obtained from national sources (Portugal's Instituto Nacional de Estatística for employment, and Direcçao de Serviços de Estudos de Mercado de Emprego for unemployment), and corrected for the factor by which each of these sources underestimates the corresponding Community LFS data for all the other NUTS2 regions that, together with Algarve, constitute the NUTS1 region Continente (Norte, Centro, Lisboa e Vale do Tejo, and Alentejo). Labour force has been calculated as the sum of the employed and the unemployed, and the unemployment rate by dividing the number of the unemployed by the labour force.

Regional unemployment rates and labour force are used to construct five series of relative unemployment rates: unemployment rates relative to the European average (Europe relative for brevity), unemployment rates relative to the average for other regions in the same Member State (State relative), unemployment rates relative to the average for contiguous regions (neighbour relative), unemployment rates relative to the average for other regions with the same broad sectoral specialisation (same specialisation relative), and unemployment rates relative to the average for other regions with a similar split of low/high educational attainment (same skill relative). In all cases averages used to construct the relative series refer only to regions included in the analysis. The information on State membership and contiguity is taken off the paper maps in Eurostat (1995).

To obtain groupings by broad sectoral specialisation, regions are classified according to the sector in the NACE-CLIO R3 classification (agricultural, forestry and fishery products; manufactured products; and market services) in which their share of total employment was highest relative to the EU average in 1988. The basis for these calculations are the total employment data by NACE-CLIO R3

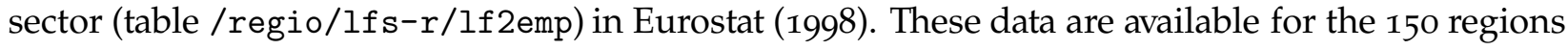
we are interested in only for 1988, but this is close enough to the beginning of the time frame considered to describe early specialisation.

To obtain groupings by low/high educational attainment, regions are classified according to the percentage of their population aged 25 to 59 in 1995 with less than upper secondary education - less than level 3 of the International Standard Classification of Education (ISCED) classification (UNESCO, 1976). These data are from table E14 in Eurostat (1997). These data are not ideal in that they refer to the adult population and not to the labour force, and they are only available for the 150 regions we are interested in for a single year, 1995. However, they are the best available at this 
level of regional disaggregation. We use them to construct nine groups of regions: regions where less than $10 \%$ of 25 to 59 year olds have less than upper secondary education, regions with more than $10 \%$ but less than $20 \%$, and so on in ten percentage points intervals until regions where more than $80 \%$ but less than $90 \%$ of 25 to 59 year olds have less than upper secondary education.

The regression analysis of Section 5 uses the same data sources as the non parametric section. For the purpose of splitting population by skill there, low skill is taken to be an educational attainment of less than upper secondary education (below level 3 of the ISCED classification). Medium skill is an educational attainment of upper secondary education (level 3 of the ISCED classification). High skill is an educational attainment of higher education (levels 5,6 , and 7 of the IsCED classification). To calculate the percentage of young population, the young are taken to be those that reached working age during the sample period (those aged between 15 and 25 in 1996). These data are obtained from table /regio/lfs-r/lf2emp) in Eurostat (1998). Initial female participation rates are those for 1986 from table /regio/lfs-r/lf2actrt) in Eurostat (1998), completed with Eurostat (1989). For the calculation of the measure of initial market potential, used as one of the instruments in the instrumental variable estimations of Section 5, 1986 regional GDP levels are from table /regioecon-r/egdp/e2gdp) in Eurostat (1998). The distance between each pair of NUTS 2 regions is the great circle distance between their geographical centres, the coordinates of which have been obtained from http://shiva.pub.getty.edu/tgn_browser/.

\section{Technical Appendix}

More familiar applications of stochastic kernels use observations on random draws from a Markov process to estimate the underlying transition characteristics of that process. In contrast, in this paper we are interested in mappings from one distribution to another distribution. For example, this may be a mapping from the distribution of Europe relative unemployment rates at one point in time to the distribution of Europe relative unemployment rates at another point in time, or it may be the mapping from the distribution of Europe relative unemployment rates to the distribution of neighbour relative unemployment rates. In this Technical Appendix, we show that standard stochastic kernels can still be used to characterise the mappings between any two distributions, providing that we are careful about the space on which we define those stochastic kernels.

Let the two distributions of interest be $\gamma$ and $\lambda$. Then we seek a mapping $\mathcal{T}^{*}$ such that $\lambda=\mathcal{T}^{*}(\gamma)$. Our underlying state space is the pair $\left(\mathrm{I}, \mathfrak{R}_{\mathrm{I}}\right)$, where $\mathrm{I}$ is the unit interval and $\mathfrak{R}_{\mathrm{I}}$ is the collection of Borel sets of the real line that are subsets of the unit interval. However, we define stochastic kernels on the more general state space $(\mathbb{R}, \mathfrak{k})$, where $\mathbb{R}$ is the real line and $\mathfrak{k}$ the collection of its Borel sets. We do so with the understanding that these definitions are valid for restrictions of the general state space to the specific unit interval state space.

Consider the most familiar case first, where we are interested in transitions over time and the distributions of interest are $\lambda_{t}$ and $\lambda_{t-1}$. Recall the standard definition of a transition function.

Transition function definition. Let $(Z, 3)$ be a measurable space. A transition function is a function $Q:(Z, 3) \rightarrow[0,1]$ that satisfies two conditions:

(i) For each $z \in Z, Q(z,$.$) is a probability measure on (Z, 3)$. 
(ii) For each $A \in 3, Q(., A)$ is a 3-measurable function.

The standard interpretation is that $Q(a, A)$ is the probability that next periods realisation lies in the set $A$, given that this period's realisation is $a$. There are two useful functions associated with the standard transition function.

\section{Two useful functions.}

1. For any 3-measurable function $f$, define $\mathcal{C} f$ by $(\mathcal{C} f)(z)=\int f\left(z^{\prime}\right) Q\left(z, \mathrm{~d} z^{\prime}\right)$, for all $z \in Z$.

2. For any probability measure $\lambda$ on $(Z, \zeta)$ define $\mathcal{C}^{*} \lambda$ by $\left(\mathcal{C}^{*} \lambda\right)(A)=\int Q(z, A) \lambda(\mathrm{d} z)$, for all $A \in 3$.

The interpretation is as follows. $(\mathcal{C} f)(z)$ is the expected value of the function next period, given that the current state is $z$. $\mathcal{C}$ maps the space of bounded functions to the space of bounded functions and is known as the Markov operator associated with $Q .\left(\mathcal{C}^{*} \lambda\right)(A)$ is the probability that the state next period lies in the set $\mathrm{A}$ if the current state is drawn according to the probability measure $\lambda$. $\mathcal{C}^{*}$ maps the space of probability measures to the space of probability measures and is known as the adjoint of $\mathcal{C}$. Thus $\lambda_{t}=\mathcal{C}^{*}\left(\lambda_{t-1}\right)$.

This $\mathcal{C}^{*}$ is closely related to the mapping $\mathcal{T}^{*}$ that we are interested in estimating. However two extensions are necessary. First, we want to allow for mappings between any two distributions, not just sequential distributions. Second, for empirical applications, we want to allow for generalised disturbances that may affect the mapping between distributions. ${ }^{22}$ The extension to any two distributions is achieved through the use of the standard stochastic kernel definition.

Stochastic kernel definition. Let $(X, \mathfrak{X})$ and $(Y, \mathcal{Y})$ be measurable spaces. Let $\phi$ be a probability measure on $(X, \mathfrak{X})$ and $\psi$ be a probability measure on $(Y, \mathcal{Y})$. A stochastic kernel relating $\phi$ to $\psi$ is a mapping $M_{\phi, \psi}:(X, \mathcal{Y}) \rightarrow[0,1]$ that satisfies three conditions:

(i) For all $y \in X$ the restriction $M_{(\phi, \psi)}(y,$.$) is a probability measure.$

(ii) For all $A \in \mathcal{Q}$ the restriction $M_{(\phi, \psi)}$ is $\mathfrak{X}$-measurable.

(iii) For all $A \in \mathcal{V}$ we have $\phi(A)=\int M_{(\phi, \psi)}(y, A) \mathrm{d} \psi(y)$.

Consider (iii). In the initial distribution, for given $y$, there is some fraction $d \psi(y)$ of regions with unemployment rates close to $y$. Count up all regions in that group whose unemployment rate subsequently fall in a given $\mathcal{Y}$-measurable subset $A \subseteq \mathbb{R}$ of the second (later/conditional) distribution. When normalised by the fraction of the total number of regions this count is precisely $M_{(\phi, \psi)}(y, A)$. Thus $M_{(\phi, \psi)}(y, A)$ is the probability that a region's realisation in the later/conditional distribution lies in the set $A$, given that the initial realisation is $y$. Evaluate the integral $\int M_{(\phi, \psi)}(y, A) \mathrm{d} \phi(y)$. This gives the fraction of regions that end up in state $A$ regardless of their initial position. If this equals $\phi(A)$ for all measurable sets $A$, then $\phi$ must be the measure associated with the subsequent distribution of unemployment rates. Conditions (i) and (ii) just ensure that this interpretation is valid. In particular, (ii) ensures that the right hand side of (iii) is a well defined Lebesgue integral,

\footnotetext{
${ }^{22}$ We have implicitly absorbed this generalised error in to our definition of $\mathcal{T}^{*}$.
} 
while (i) ensures that the right hand side of (iii) is a weighted average of probability measures and thus is itself a probability measure. It is easy to see that a transition kernel is a stochastic kernel for which the two spaces $(X, \mathfrak{X})$ and $(Y, \mathcal{Y})$ are the same.

To allow for generalised disturbances we need to be able to model random elements drawn from a collection of probability measures. Following Quah (1997a) we proceed as follows. First we define a Banach space that contains all possible probability measures. We then use this Banach space and suitably defined open sets on that space to define a measurable space which we can, in turn, use to model random elements drawn from collections of probability measures.

Let $\boldsymbol{B}(\mathbb{R}, \mathfrak{R})$ be the Banach space of bounded finitely additive set functions on the measurable space $(\mathbb{R}, \mathfrak{R})$ with total variation norm

$$
\text { for all } \phi \text { in } \boldsymbol{B}(\mathbb{R}, \mathfrak{R}):\|\phi\|=\sup \sum_{j}\left|\phi\left(A_{j}\right)\right|,
$$

where the supremum is taken over all $\left\{A_{j}: j=1,2, \ldots n\right\}$ finite measurable partitions of $\mathbb{R}$.

Empirical distributions on $\mathbb{R}$ are identified with probability measures on $(\mathbb{R}, \mathfrak{R})$. Probability measures are elements of $\boldsymbol{B}(\mathbb{R}, \mathfrak{R})$ that are countably additive and assign value one to the entire space $\mathbb{R}$. We use the set of bounded finitely additive set functions, because a collection of probability measures can never form a linear space. The set of boundedly-additive set functions includes probability measures and does form a linear space. We can then use the total variation norm to make this space Banach. Once probability measures are embedded in a Banach space, it makes sense to talk about two probability measures (and the associated distributions) getting closer to one another. Further, if we define a measure of distance, we can define open sets of probability measures (relative to this distance measure) and use these open sets to generate (Borel) $\sigma$-algebras on the Banach space. Given such a $\sigma$-algebra, we can model random elements drawn from collections of probability measures. This is the data of interest when we are modelling the dynamics of distributions.

Let $2 \mathfrak{3}$ denote the $\sigma$-algebra generated by the open sub-sets (relative to the total variation norm topology) of $\boldsymbol{B}(\mathbb{R}, \mathfrak{Z})$. Then $(\boldsymbol{B}, \mathfrak{2})$ is another measurable space. By construction, each $\phi_{i}$ associated with an observed (or derived) empirical cross sectional distribution $F_{i}$ is a member of $(\boldsymbol{B}, \mathfrak{2} \mathbf{3})$. If $(\Omega, \mathfrak{f}, \operatorname{Pr})$ is the underlying probability space, then $\phi_{i}$ is the value of an $\mathfrak{f} / \mathbf{2}$-measurable map $\Phi(\Omega, \mathfrak{f}) \rightarrow(\boldsymbol{B}, \mathfrak{2} \mathbf{3})$. We can define probability measures on $(\boldsymbol{B}, \mathfrak{2})$ that will allow us to deal with the generalised disturbances that affect the mapping between distributions.

Now, let $\boldsymbol{b}(\mathbb{R}, \mathfrak{R})$ be the Banach space under sup norm of bounded measurable function on $(\mathbb{R}, \mathfrak{R})$. Fix a stochastic kernel $M$ and construct an operator $\mathcal{T}$ (similar to $\mathcal{C}$ ) that maps the space of bounded measurable functions on to itself:

$$
\text { for any } f \in \boldsymbol{b}(\mathbb{R}, \mathfrak{R}) \text { define } \mathcal{T} f \text { by }(\mathcal{T} f)(z)=\int f\left(z^{\prime}\right) M\left(z, \mathrm{~d} z^{\prime}\right) \text {, for all } z \in \mathbb{R} \text {. }
$$

This mapping has the same interpretation as $\mathcal{C}$ in the (useful) function 1 above. Now we can denote the adjoint of $\mathcal{T}$ by $\mathcal{T}^{*}$. Thus:

for any probability measure $\lambda$ on $(\mathbb{R}, \mathfrak{R})$ define $\mathcal{T}^{*} \lambda$ by $\left(\mathcal{T}^{*} \lambda\right)(A)=\int M(z, A) \lambda(\mathrm{d} z)$, for all $A \in \mathfrak{R}$. 
From the Riesz Representation Theorem, the dual space of $\boldsymbol{b}(\mathbb{R}, \mathfrak{Z})$ is $\boldsymbol{B}(\mathbb{R}, \mathfrak{R})$, the collection of bounded finitely additive set functions. Thus $\mathcal{T}^{*}$ maps the collection of bounded finitely additive set functions on to itself. It is also precisely the mapping (iii) in the stochastic kernel definition. In our empirical analysis, we estimate $M(\phi, \psi)\left(y_{1}.\right)$ (the probability distribution of a region's realisation in the later/conditional distribution given that the initial realisation is $y$ ) for a whole range of $y$ values. Here, we have shown that this does indeed allow us to trace out $\mathcal{T}^{*}$, the generalised mapping between any two distributions. 